\title{
Curcumin Protects against 1-Methyl-4-phenylpyridinium Ion- and Lipopolysaccharide-Induced Cytotoxicities in the Mouse Mesencephalic Astrocyte via Inhibiting the Cytochrome P450 2E1
}

\author{
Hai-Yan Gui, Rui-Ni Chen, Yan Peng, Jin-Hua Hu, Zhao Mao, Rui Ning, Wei Shang, \\ Wei Liu, Jing Xiong, Gang Hu, and Jian Yang
}

Department of Pharmacology, Nanjing Medical University, 140 Hanzhong Road, Jiangsu, Nanjing 210029, China

Correspondence should be addressed to Jian Yang; jianyang@njmu.edu.cn

Received 11 April 2013; Accepted 22 May 2013

Academic Editor: Sedigheh Asgary

Copyright (C) 2013 Hai-Yan Gui et al. This is an open access article distributed under the Creative Commons Attribution License, which permits unrestricted use, distribution, and reproduction in any medium, provided the original work is properly cited.

Curcumin is extracted from the rhizomes of the ginger family plant Curcuma longa L., which has a good protection for liver, kidney, and immune system. However, there is little information about its contribution in protection of astrocytes recently. The present study was undertaken to elucidate the protective effect of curcumin, an herbal antioxidant, on 1-methyl-4-phenylpyridinium ion$\left(\mathrm{MPP}^{+}-\right)$and lipopolysaccharide- (LPS-) induced cytotoxicities, as well as the underlying mechanisms by using primary mouse mesencephalic astrocytes. The results showed that curcumin protected the mesencephalic astrocytes from MPP ${ }^{+}$- and LPS-induced toxicities along with reducing reactive oxygen species $(P<0.05)$ and maleic dialdehyde $(P<0.05)$ sufficiently. Moreover, curcumin significantly inhibited the cytochrome P450 2E1 (CYP2E1) expression $(P<0.01$ at mRNA level, $P<0.05$ at protein level) and its activity $(P<0.05)$ sufficiently induced by $\mathrm{MPP}^{+}$and LPS in the mouse mesencephalic astrocytes. And curcumin as well as diallyl sulphide, a CYP2E1 positive inhibitor, ameliorated $\mathrm{MPP}^{+}$- and LPS-induced mouse mesencephalic astrocytes damage. Accordingly, curcumin protects against $\mathrm{MPP}^{+}$- and LPS-induced cytotoxicities in the mouse mesencephalic astrocyte via inhibiting the CYP2E1 expression and activity.

\section{Introduction}

Curcumin (1,7-bis[4-hydroxy 3-methoxy phenyl]-1,6-heptadiene-3,5-dione, Cur) is extracted from the rhizomes of the ginger family plant Curcuma longa (Curcuma longa L.). Studies suggest that Cur has antiinflammatory [1], antiatherosclerosis [2], antitumor [3], antioxidation [4], scavenging-free radical [5], and other pharmacological effects [6]. Animal model data show that dietary Cur is a strong candidate in the prevention or treatment of major disabling agerelated neurodegenerative diseases like Alzheimer's disease, Parkinson's disease (PD), and stroke [7]. Several studies in different experimental models of PD strongly support the clinical application of Cur in PD $[8,9]$. However, the underlying mechanisms of Cur treatment of PD are limited.
Astrocytes are the most numerous nonneuronal celltype in central nervous system and make up 50\% of human brain volume. They produce neurotrophic factor, remove toxins and debris from the extracellular space, and regulate innate immunity in the central nervous system [10]. In addition, astrocytes are allowed by some specific enzyme systems to metabolize ammonia, glutamate, free radicals, xenobiotics, and metals. Hence, they protect the neurons from the endogenous and exogenous toxicities. On the other hand, evidence also showed that astrocytes play a vital part in the secondary amplification of cell injury in multiple neurodegenerative disorders such as Parkinson's disease. PD is the second most prevalent neurodegenerative disease. The major pathological features are the loss of dopaminergic neurons in substantia nigra compact, the presence of Lewy's bodies, and the significant decrease of dopamine level in 
the striatum [11, 12]. Although the exact etiology of the PD is unknown, many studies suggest that multiple factors may be involved, such as heredity, environment, oxidative stress, inflammation, and decline in growth factors [13]. Oxidative stress, which results from the imbalance of reactive oxygen species (ROS) generation and clearance, is one of the important pathogenesis of PD [14]. ROS generation may vary considerably depending on cytochrome P450 enzymes (CYPs). Compared with other CYPs, cytochrome P450 2E1 (CYP2E1) exhibits a higher rate of oxidase activity that causes the formation of ROS during the catalytic cycle. The ROS generation is likely to initiate lipid peroxidation and damage cell membranes $[15,16]$. In the brain, CYP2E1 is constitutively expressed in hippocampal pyramid neurons, astrocytes, and endothelial cells [17], and CYP2E1 has been found to be inducible and catalytically active in the central nervous system [18-20]. It has been suggested that 1-methyl4-phenylpyridinium ion $\left(\mathrm{MPP}^{+}\right.$, the ion form of 1-methyl-4phenyl-1,2,3,6-tetrahydropyridine, MPTP) and lipopolysaccharide (LPS) increased the expression of CYP2E1 and induced oxidative stress in astrocytes $[18,19]$. The increasing evidence shows that CYP2E1 is involved in the MPTPinduced mouse model of PD [21, 22].

In this study, we demonstrated that Cur had the cytoprotection against $\mathrm{MPP}^{+}$- and LPS-induced toxicities in the primary mouse mesencephalic astrocytes. Meanwhile, Cur decreased the increased ROS and maleic dialdehyde (MDA) amount in the primary culture mesencephalic astrocytes exposed to $\mathrm{MPP}^{+}$and LPS. Combination with an increase of CYP2E1 induced by $\mathrm{MPP}^{+}$and LPS in astrocytes [18, 19], we hypothesized that Cur protects against $\mathrm{MPP}^{+}$- and LPS-induced mouse mesencephalic astrocyte damage via inhibiting the CYP2E1 expression and activity.

\section{Materials and Methods}

2.1. Animal and Materials. C57BL/6J mice were kept under environmentally controlled conditions (ambient temperature, $22 \pm 1^{\circ} \mathrm{C}$; humidity, $40 \%$ ) on a 12 -hour light-dark cycle with food and water ad libitum. All the experiments were approved by Institutional Animal Care and Use Committee (IACUC) of Nanjing Medical University. And efforts were made to minimize animal suffering and to reduce the number of animals used for the experiments.

Dulbecco's modified eagle's medium (DMEM) was from Gibco (Gibco, Grand Island, NY, USA). MPP ${ }^{+}$, LPS, and curcumin (98\% purity) were purchased from Sigma-Aldrich (St. Louis, MO, USA). Ethyl alcohol (EtOH) was from Sinopharm (Shanghai, China). Antibody to CYP2E1 was obtained from Abcam (Cambridge, UK). SYBR Premix Ex Taq kit was purchased from Biotechnology Limited Company (Takara, Japan). Tryptase and MTT were purchased from AMRESCO (Solon, OH, USA). Fetal bovine serum (FBS) was purchased from Sijiqing (Hangzhou, China). Trizol was from Invitrogen Life (Carlsbad, CA, USA). MLV and RNase inhibitor were purchased from Promega (Madison, WI, USA). $2^{\prime}, 7^{\prime}$ dichlorofluorescein diacetate (DCFH-DA) was purchased from Biyuntian (Shanghai, China). Lactate dehydrogenase
( $\mathrm{LDH}$ ), MDA, $\mathrm{H}_{2} \mathrm{O}_{2}$, and glutathione peroxidase (GSH-Px) diagnostic kits were from Nanjing Jiancheng Bioengineering Company (Nanjing, China), and the other chemicals were all obtained from Sigma unless otherwise stated.

\subsection{Primary Mesencephalic Astrocyte Culture. Primary} mouse mesencephalic astrocyte culture was prepared from midbrain of newborn of $\mathrm{C} 57 \mathrm{BL} / 6 \mathrm{~J}$ mice as described previously [23] with slight modifications. Briefly, postnatal (P1-P2) mice were killed by rapid decapitation, the meninges were removed, and the midbrain parts were separated. The midbrain parts were dissociated with $0.25 \%$ tryptase at $37^{\circ} \mathrm{C}$ and terminated by DMEM supplemented with 10\% FBS and penicillin/streptomycin. After centrifugation at $1500 \mathrm{rpm}$ for $5 \mathrm{~min}$, the cell pellets were resuspended and seeded on polylysine coated flask. The cultures were maintained at $37^{\circ} \mathrm{C}$ in a humidified $5 \% \mathrm{CO}_{2}-95 \%$ air atmosphere [24]. Culture medium was replaced $24 \mathrm{~h}$ later and then changed every 2-3 days. After reaching a confluent monolayer of glial cells (10-14 days), mesencephalic astrocytes were replated on other polylysine-coated flasks. The tertiary cultures are $\sim 95-98 \%$ astrocytes, with only $\sim 2-5 \%$ microglial cells as determined by immunocytochemical staining with antiGFAP antibody as well as double immunofluorescence for GFAP and microglial marker Iba-1 [24]. The mesencephalic astrocytes were seeded on polylysine coated 6-, 12-, 24-, or 96-well plates for corresponding experiments.

2.3. Cell Viability. Cell viability was detected by 3-(4,5-dimethylthiazol-2-yl) 2,5-diphenyltetrazolium bromide (MTT) assay. Mesencephalic astrocytes were seeded in polylysine coated 96-well plates at a density of $1 \times 10^{4}$ cells/well, pretreated with Cur, diallyl sulphide (DAS), or vehicle (DMSO), and then incubated with $\mathrm{MPP}^{+}(100 \mu \mathrm{M})$ and LPS $(1 \mu \mathrm{g} / \mathrm{mL})$ for $48 \mathrm{~h}$. Then $20 \mu \mathrm{L}$ of $5 \mathrm{mg} / \mathrm{mL}$ MTT was added to cells, and cells were incubated at $37^{\circ} \mathrm{C}$ for another $4 \mathrm{~h}$. The culture medium was discarded, and $100 \mu \mathrm{L}$ DMSO was used to dissolve the precipitate. The absorbance was measured at $570 \mathrm{~nm}$ using an Automated Microplated Reader ELx800 (BioTek). The cytotoxicity assessment was exhibited by cytotoxicity index, which was calculated as previously described [25]. Each treatment was in quadruplicate. And data came from three independent experiments.

2.4. Determination of Lactate Dehydrogenase Release. Mesencephalic astrocytes injury (cytotoxicity) was quantitatively assessed by the measurement of lactate dehydrogenase (LDH) leakage. $\mathrm{LDH}$ release in culture medium in the presence of DMSO or Cur for 30 min followed by the addition of $\mathrm{MPP}^{+}$ and LPS for $48 \mathrm{~h}$ was measured using an LDH diagnostic kit according to the manufacturer's instruction. LDH amount was calculated by measuring absorbance at $450 \mathrm{~nm}$. The data were represented as a percentage of $\mathrm{LDH}$ release of control group. Each treatment was in quadruplicate. And data came from three independent experiments.

2.5. Hoechst 33342 Staining. To quantify apoptotic mesencephalic astrocytes, mesencephalic astrocytic monolayer was 
stained with Hoechst 33324. Mesencephalic astrocytes were seeded in polylysine coated 24 -well plates and pretreated with Cur or vehicle (DMSO) for $30 \mathrm{~min}$ and then incubated with $\mathrm{MPP}^{+}(100 \mu \mathrm{M})$ and LPS $(1 \mu \mathrm{g} / \mathrm{mL})$ for $48 \mathrm{~h}$. The cells were fixed with $4 \%$ paraformaldehyde for $20 \mathrm{~min}$, washed with PBS, and then incubated with Hoechst33342 $(1 \mu \mathrm{g} / \mathrm{mL})$ for 10 min. After washing with PBS, the morphological features of apoptosis (chromatin condensation) were monitored by fluorescent microscope (Olympus, Japan) (Acquisition software: DP2-BSW). Cells with condensed nuclei or nuclear condensations were scored as apoptotic mesencephalic astrocytes [26], and each treatment was performed in triplicate.

\subsection{Measurement of Reactive Oxygen Species Generation.} Formation of ROS was evaluated using $2^{\prime}, 7^{\prime}$-dichlorofluorescein diacetate (DCFH-DA), a membrane-permeable probe. After different treatments, mesencephalic astrocytes were loaded with DCFH-DA ( $50 \mu \mathrm{M}$ final concentration) in DMEM for 30 min in the dark and fixed by $4 \%$ formaldehyde. After rinsing cells with PBS three times, cells were observed using a fluorescent microscope. At least 400 cells from 12 randomly selected fields per dish were counted. Then, the cells were collected to measure the fluorescence intensity at the excitation wavelength of $485 \mathrm{~nm}$ and the emission wavelength of $530 \mathrm{~nm}$ [27]. Each treatment was performed in triplicate. And data came from three independent experiments.

2.7. Determination of Lipid Peroxidation Products. Mesencephalic astrocytes were seeded in polylysine coated 24well plates at a density of $2 \times 10^{5}$ cells/well. Cells were pretreated with Cur or vehicle (DMSO) for $30 \mathrm{~min}$ and then incubated with $\mathrm{MPP}^{+}(100 \mu \mathrm{M})$ and LPS $(1 \mu \mathrm{g} / \mathrm{mL}) 400 \mu \mathrm{L}$ for $48 \mathrm{~h}$. Lipid peroxidation products, namely, the amount of MDA formed by the 2-thiobarbituric acid reaction as thiobarbituric acid reactive substances in the supernatant [28], were measured by using a commercial MDA kit. The spectrophotometric absorbance was assessed at $532 \mathrm{~nm}$ in accordance with the manufacturer's instructions. The results were expressed as $\mathrm{nmol} / \mathrm{mL}$ in $2 \times 10^{5}$ cells. Each treatment was in quadruplicate. And data came from three independent experiments.

2.8. The $\mathrm{H}_{2} \mathrm{O}_{2}$ Production Assay. Mesencephalic astrocytes were seeded in polylysine coated 12 -well plates at a density of $5 \times 10^{6}$ cells/well. Cells were pretreated with Cur or vehicle (DMSO) for $30 \mathrm{~min}$ and then incubated with $\mathrm{MPP}^{+}(100 \mu \mathrm{M})$ and LPS $(1 \mu \mathrm{g} / \mathrm{mL}) 800 \mu \mathrm{L}$ for $48 \mathrm{~h}$. The supernatants were used to measure $\mathrm{H}_{2} \mathrm{O}_{2}$ production using a $\mathrm{H}_{2} \mathrm{O}_{2}$ diagnostic kit, essentially according to the manufacturer's manual. The $\mathrm{H}_{2} \mathrm{O}_{2}$ products were calculated with a calculation formula provided by the manufacturer's instruction. The $\mathrm{H}_{2} \mathrm{O}_{2}$ product was represented as $\mu \mathrm{mol} / \mathrm{L}$ in $5 \times 10^{5}$ cells. Each treatment was in quadruplicate. And data came from three independent experiments.

2.9. GSH-Px Activity Assay. Mesencephalic astrocytes were seeded in polylysine coated 12 -well plates at a density of $5 \times 10^{6}$ cells/well. Cells were pretreated with Cur or vehicle (DMSO) for $30 \mathrm{~min}$ and then incubated with $\mathrm{MPP}^{+}(100 \mu \mathrm{M})$ and LPS $(1 \mu \mathrm{g} / \mathrm{mL})$ for $48 \mathrm{~h}$. The media were discarded. And cells were rinsed with PBS and harvested in $200 \mu \mathrm{L}$ of PBS. The cell suspension was sonicated by a sonifier, and cell debris was removed by centrifugation at $1,2000 \mathrm{~g}$ for $15 \mathrm{~min}$ at $4^{\circ} \mathrm{C}$ [29]. The GSH-Px activity of cells was measured by using a GSH-Px assay kit, essentially according to the manufacturer's manual. The GSH-Px activity of cells was calculated with a calculation formula provided by the manufacturer's instruction. The GSH-Px activity was represented as unit/min/gram protein. Each treatment was in quadruplicate. And data came from three independent experiments.

2.10. Immunocytochemistry. Mesencephalic astrocytes were seeded in polylysine coated 24-well plates at a density of $5 \times 10^{4}$ cells/well in growth medium. After pretreated with Cur $(3 \mu \mathrm{M})$ or DMSO for $30 \mathrm{~min}$, cells were incubated with $\mathrm{MPP}^{+}$, LPS, and EtOH for $48 \mathrm{~h}$. For immunocytochemistry, the cells were fixed with $4 \%$ paraformaldehyde for $30 \mathrm{~min}$ and then permeabilized with $0.02 \%$ Triton X-100 containing $0.1 \%$ BSA for $1 \mathrm{~h}$. Immune complexes were formed by incubating cells with primary antibody CYP2E1 (1:400) overnight at $4^{\circ} \mathrm{C}$ followed by incubation with anti-rabbit secondary antibody $(1: 800)$ for $1 \mathrm{~h}$ at $37^{\circ} \mathrm{C}$ and visualized by DAB. Cell morphology was monitored using an inverted light microscope (Olympus, Japan, Acquisition software: DP2BSW). Negative control staining was performed without the primary antibodies. EtOH treatment was a positive control of CYP2E1 inducer. After immunocytochemical staining, the astrocytes were captured at a magnification of 200x. Three visions from each well were randomly selected in order to analyze immunoreactive productions of CYP2E1 by using Leica Image Processing and Analysis System. Each treatment was performed in triplicate. And data came from three independent experiments.

2.11. Quantitative Real-Time Polymerase Chain Reaction. Total RNA was prepared from mesencephalic astrocytes using Trizol reagent according to the manufacturer's instruction. The first-strand cDNA was synthesized using total RNA $(2 \mu \mathrm{g})$ at $70^{\circ} \mathrm{C}$ for $5 \mathrm{~min}, 42^{\circ} \mathrm{C}$ for $60 \mathrm{~min}$, and $95^{\circ} \mathrm{C}$ for $10 \mathrm{~min}$ by using an oligo (dT) primer, MMLV reverse transcription, RNase inhibitor, and dNTP mix in a total volume of $20 \mu \mathrm{L}$. The cDNAs were quantitative. PCR was conducted with SYBR Premix Ex Taq kit (Takara, Japan). $20 \mu \mathrm{L}$ of PCR mix contained $10 \mu \mathrm{L}$ of SYBR Green PCR master mix $(2 \times), 1 \mu \mathrm{L}$ of each primer, $2 \mu \mathrm{L}$ of $\mathrm{cDNA}$ as template, and $6 \mu \mathrm{L}$ of water. The PCR amplification and quantification were done in an Applied Biosystems 7300 RealTime PCR System with SDS software (Applied Biosystems, Warrington, UK). After initial denaturation at $95^{\circ} \mathrm{C}$ for $30 \mathrm{~s}$, amplifications were carried out for 40 cycles at $95^{\circ} \mathrm{C}$ for $5 \mathrm{~s}$ and $60^{\circ} \mathrm{C}$ for $31 \mathrm{~s}$. The signals from each target gene were normalized based on the signal from the corresponding GAPDH. PCR primers used in this study were as follows: (1) 
GAPDH: Forward, 5'-GTATGTCGTGGAGTCTACTGGTGTC-3', Reverse, 5'-GGTGCAGGATGCATTGCTGACATTC-3'; (2) CYP2E1: Forward, 5'-AAGCGCTTCGGG-

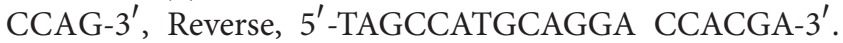
Each treatment was performed in triplicate. And data came from three independent experiments.

2.12. Cytochrome P450 2E1 (CYP2E1) Activity. CYP2E1 activity was measured based on the rate of oxidation of $\mathrm{p}$ nitrophenol (PNP) to p-nitrocatechol in the presence of NADPH by modification of the methods of Reinke and Moyer [30] and Koop [31]. Briefly, after treatment, cells were rinsed with PBS and harvested in $50 \mu \mathrm{L}$ of $100 \mathrm{mM}$ potassium phosphate buffer, $\mathrm{pH}$ 7.4. The cell suspension was sonicated by a sonifier (Nanjing, China), and the cell debris was removed by centrifugation at $12,000 \mathrm{~g}$ for $15 \mathrm{~min}$ at $4^{\circ} \mathrm{C}$. The protein concentration of the samples was estimated with the BCA kit. Standards and blanks were assessed simultaneously. The activity was determined in a final volume of $100 \mu \mathrm{L}$ containing

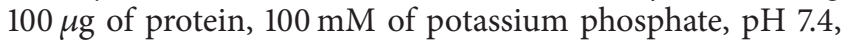
$0.1 \mathrm{mM}$ of PNP, $1 \mathrm{mM}$ of $\mathrm{NADPH}$ and $5 \mathrm{mM}$ of $\mathrm{MgCl}_{2}$ followed by incubation at $37^{\circ} \mathrm{C}$ for $10 \mathrm{~min}$. The reaction was terminated by the addition of $20 \mu \mathrm{L}$ of chilled trichloroacetic acid $(20 \%, w / v)$ and centrifuged at $10,000 \times \mathrm{g}$ for $5 \mathrm{~min}$. After being centrifuged, $100 \mu \mathrm{L}$ of the supernatant was added to $10 \mu \mathrm{L} 10 \mathrm{~N}$ of sodium hydroxide. 4-Nitroatechol formation was then spectrophotometrically determined at $510 \mathrm{~nm}$. A standard curve with 4-nitrocatehol was used to calculate CYP2E1 activity. The results were expressed as nmol per minute per mg of protein. Each treatment was in quadruplicate. Several controls were performed including incubation protein or regeneration system. And data came from three independent experiments.

2.13. Statistical Analysis. All data were presented as the mean \pm SD (standard deviation). Statistical analysis between control group and Cur treatment group was performed with two-tailed independent Student's $t$-tests, using SPSS 10.0 for Windows (SPSS, Inc., Chicago, IL, USA). And statistical analysis for multiple comparisons was performed by a oneway ANOVA test with Turkey's corrections. Differences were considered statistically significant when the $P$ value was less than $0.05,0.01$, or 0.001 .

\section{Results and Discussion}

\subsection{Results}

3.1.1. Cur at Low Concentration Had No Cytotoxicity to the Mouse Mesencephalic Astrocytes. As shown in Figure 1(a), the viability of the mesencephalic astrocytes was unchanged when cells were treated with Cur from $1 \mu \mathrm{M}$ to $10 \mu \mathrm{M}$ compared to that of the control. However, a significant decrease of the mesencephalic astrocytes viability was observed when cells were treated with $30 \mu \mathrm{M}$ and $50 \mu \mathrm{M}$ of Cur. LDH release in culture medium was employed to indicate cell membrane damage. Similar to MTT assay (Figure 1(b)), Cur at low concentrations $(1 \mu \mathrm{M}-10 \mu \mathrm{M})$ did not change the
$\mathrm{LDH}$ release. But Cur at high concentrations $(30 \mu \mathrm{M}$ and $50 \mu \mathrm{M}$ ) significantly increased the LDH release in the mesencephalic astrocytes. Consistently, mesencephalic astrocytes, which were treated with low concentrations $(1 \mu \mathrm{M}, 3 \mu \mathrm{M}$, and $10 \mu \mathrm{M}$ ) of Cur, possessed mainly rounded or oval body and exhibited extensive processes. The body and processes of mesencephalic astrocytes were near normalcy (control). In contrast, the body of mesencephalic astrocytes which were treated with high concentrations $(30 \mu \mathrm{M}, 50 \mu \mathrm{M})$ of Cur became more asperous with shrunken morphologies, and processes of mesencephalic astrocytes were reduced in size and decreased in number (Figure 1(c)).

The data suggested that Cur at low concentrations had no cytotoxicity but at high concentrations had some cytotoxicities in the mouse mesencephalic astrocytes. So we chose the low concentrations of Cur $(1 \mu \mathrm{M}, 3 \mu \mathrm{M}$, and $10 \mu \mathrm{M})$ for subsequent experiments.

\subsubsection{Cur Ameliorated the Cell Damage Induced by MPP} and LPS in the Mouse Mesencephalic Astrocytes. It has been reported that exposure to $\mathrm{MPP}^{+}$and LPS potentially results in astrocytes damage or death [24]. We therefore investigated whether Cur protected against $\mathrm{MPP}^{+}$and LPS in the mesencephalic astrocytes. The results showed that Cur $(1 \mu \mathrm{M}, 3 \mu \mathrm{M}$, and $10 \mu \mathrm{M})$ attenuated the reduction of cell viability and the increase of $\mathrm{LDH}$ release induced by $\mathrm{MPP}^{+}$and LPS in the primary cultured mouse mesencephalic astrocytes. The most significant protective effect of Cur was at $3 \mu \mathrm{M}$ (Figures 2(a) and $2(\mathrm{~b}))$. Therefore, $3 \mu \mathrm{M}$ of Cur was chosen to explore the mechanism in the following experiments.

The nuclear staining assay was used to assess the morphological changes of apoptosis in the mesencephalic astrocytes. The normal cells exhibited uniformly dispersed chromatin and intact cell membrane. The impaired cells appeared typical characteristics of apoptosis, including apoptotic nuclear condensation. Similar to the results of cell viability and $\mathrm{LDH}$ release, Cur attenuated the mesencephalic astrocytes apoptosis induced by $\mathrm{MPP}^{+}$and LPS (Figure 2(c)).

The data suggested that Cur attenuated the mouse mesencephalic astrocyte damage induced by $\mathrm{MPP}^{+}$and LPS (Figures 2(a), 2(b), and 2(c)).

3.1.3. Cur Decreased the ROS and MDA Production Induced by $\mathrm{MPP}^{+}$and LPS in the Mouse Mesencephalic Astrocytes. Since ROS played an important role in cell death, we next investigated the intracellular ROS formation using a fluorescent sensitive probe (DCFH-DA). As shown in Figures 3(a) and 3(b), when the mesencephalic astrocytes were treated with $\mathrm{MPP}^{+}$ and LPS for $48 \mathrm{~h}$, the intracellular ROS level significantly increased compared with that of the control, respectively. The results revealed that $\mathrm{MPP}^{+}$and LPS enhanced ROS generation in the primary mouse mesencephalic astrocytes. Cotreatment with $3 \mu \mathrm{M}$ of Cur reduced the intracellular ROS production and significantly attenuated an increase of ROS caused by $\mathrm{MPP}^{+}$and LPS in the primary mouse mesencephalic astrocytes (Figures 3(a) and 3(b)).

ROS can initiate lipid peroxidation; MDA is one of the most frequently used indicators of lipid peroxidation. When 


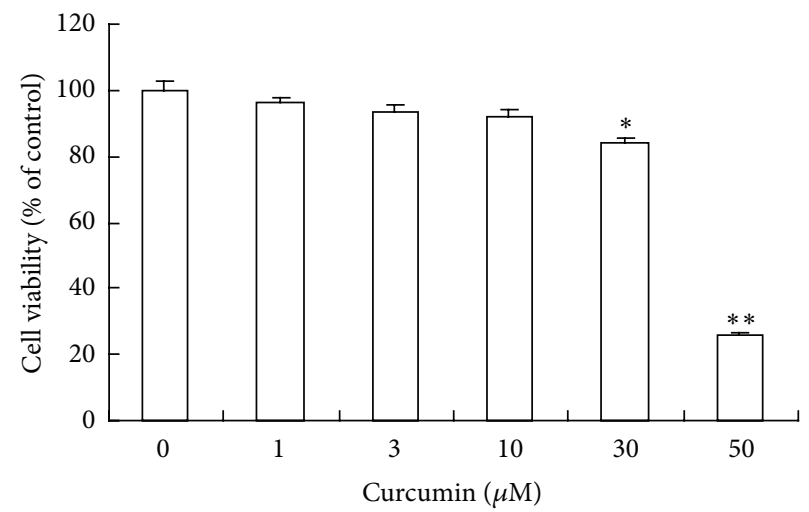

(a)
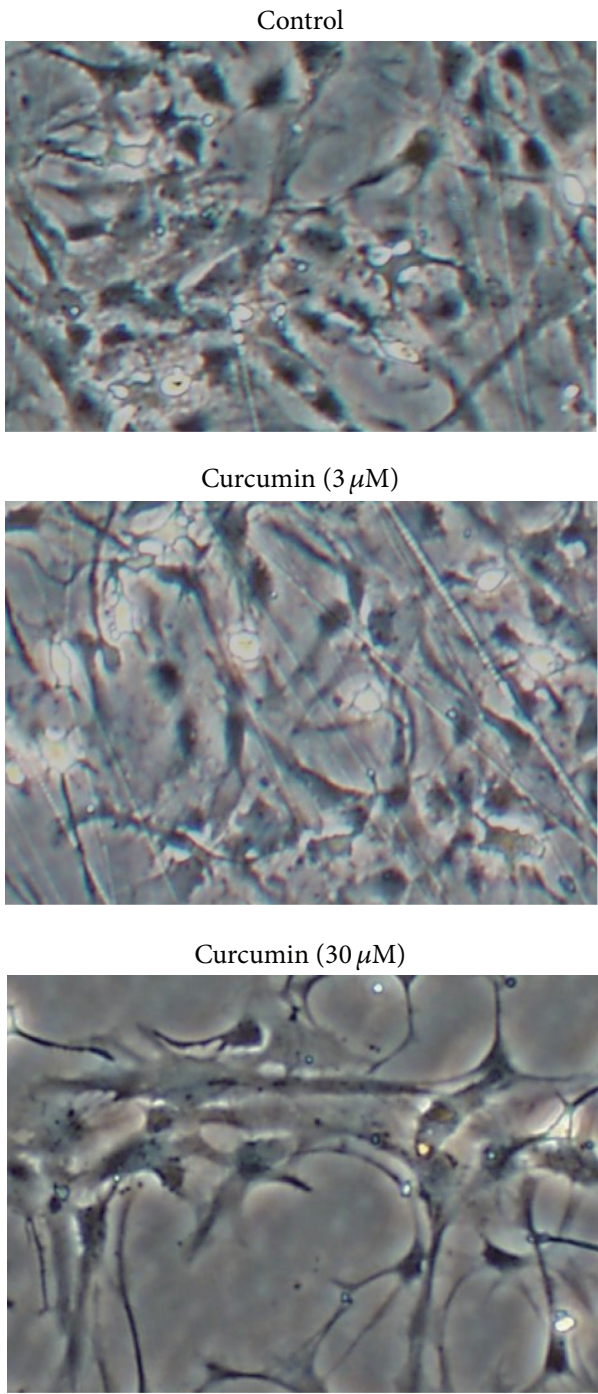

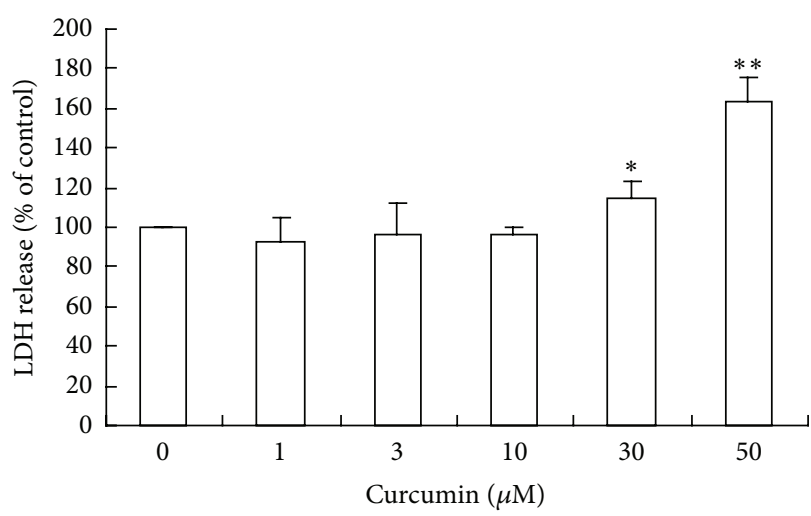

(b)
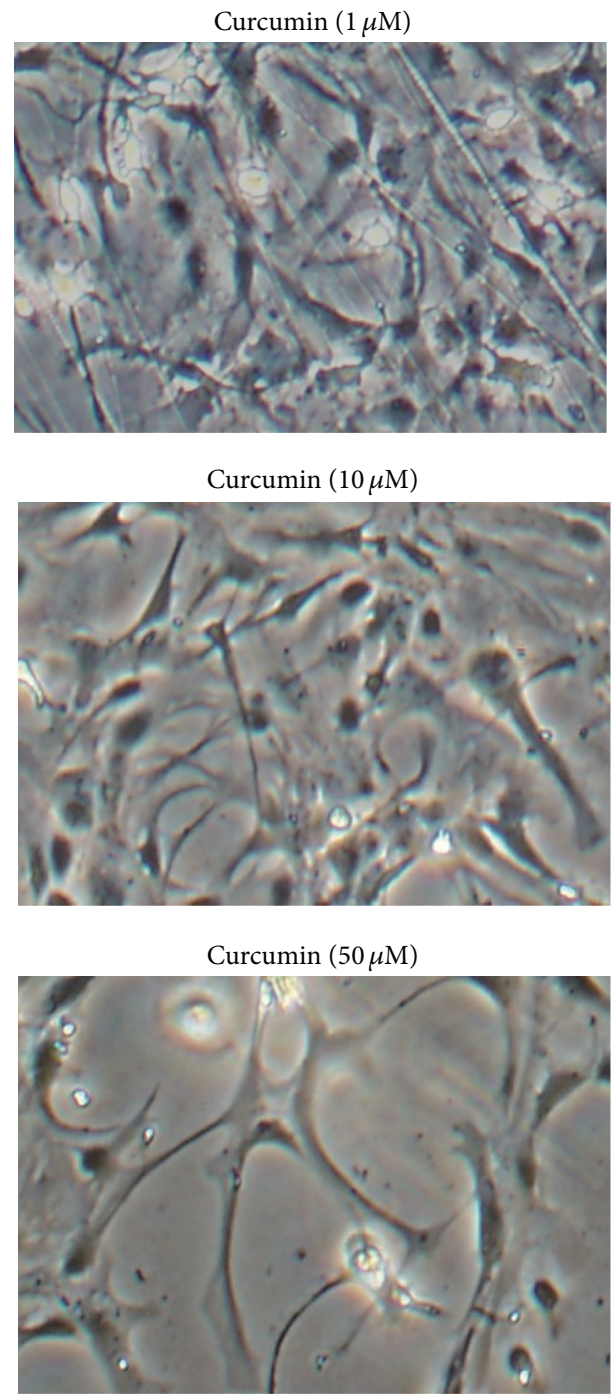

(c)

FIGURE 1: Effects of Cur on the cytotoxicity of the primary cultured mesencephalic astrocytes. (a) Cell viability of the primary cultured mesencephalic astrocytes. (b) LDH release of the primary cultured mesencephalic astrocytes. (c) Morphologies of the primary cultured mesencephalic astrocytes. Primary cultured mesencephalic astrocytes were treated with the indicated concentrations of Cur $(1,3,10,30$, and 50) $(\mu \mathrm{M})$ for $48 \mathrm{~h}$. The cell viability was determined with MTT. LDH release was measured by the LDH diagnostic kit. Morphological analysis was taken under bright field (magnification $40 \mathrm{x}$ ). And data are presented as mean $\pm \mathrm{SD}$ of three independent experiments, ${ }^{*} P<0.05$ and ${ }^{* *} P<0.01$ compared to the control group. 

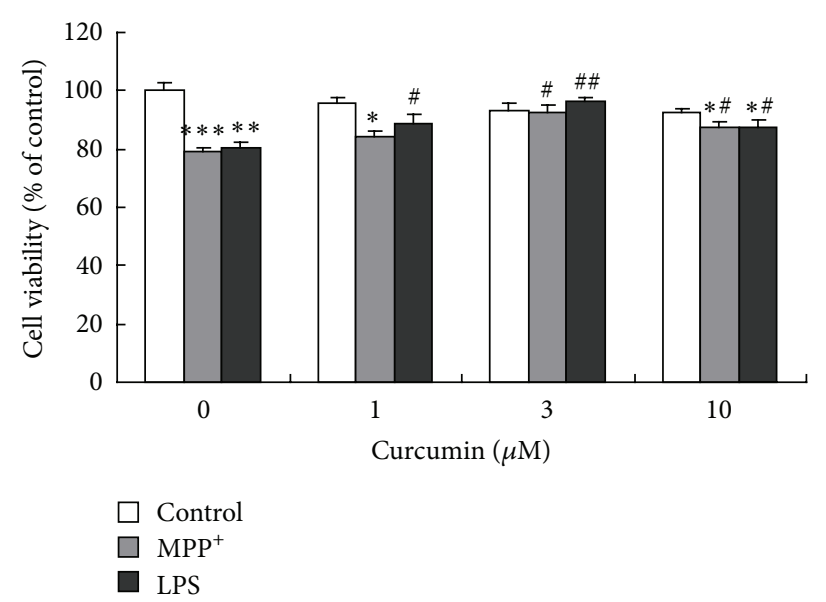

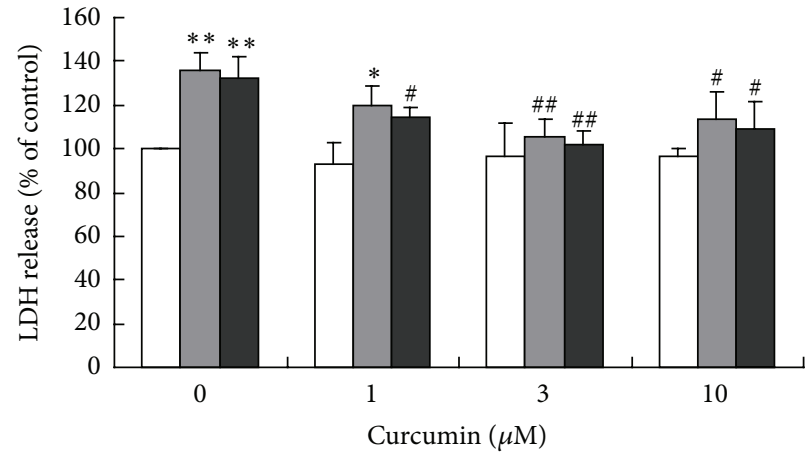

$\square$ Control
$\square$ MPP $^{+}$
$\square$ LPS (a)

Control

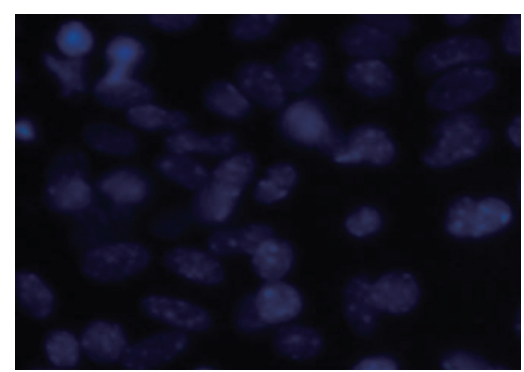

Curcumin

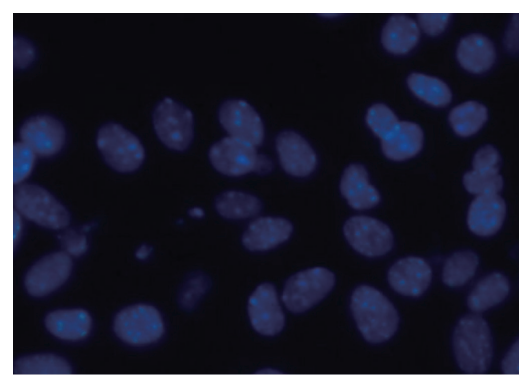

$\mathrm{MPP}^{+}$

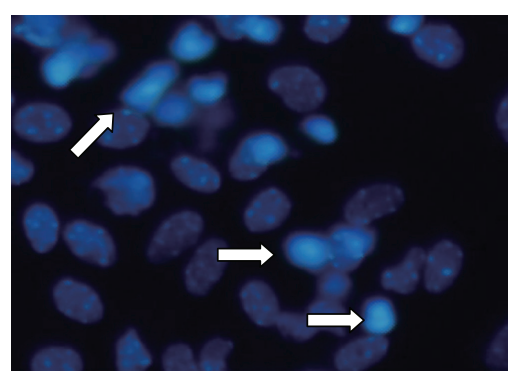

$M+C$

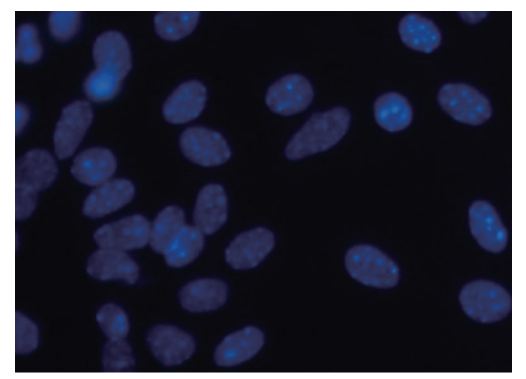

(c) (b)

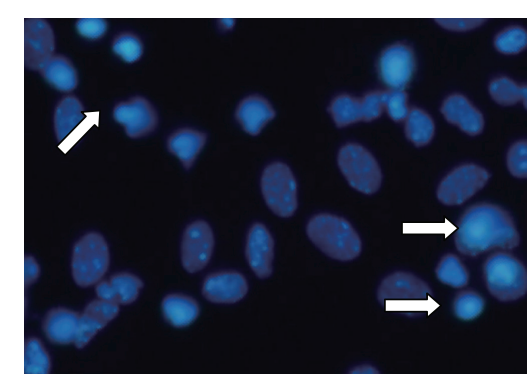

$\mathrm{L}+\mathrm{C}$

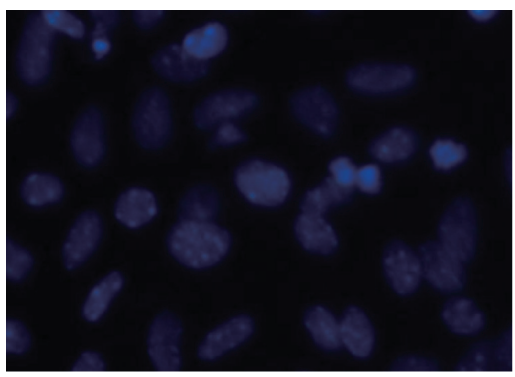

FIGURE 2: Cur protected the mesencephalic astrocytes from cytotoxicity induced by $\mathrm{MPP}^{+}$and LPS. (a) Cell viability of the mesencephalic astrocytes. (b) LDH release of the mesencephalic astrocytes. (c) Apoptosis of the mesencephalic astrocytes. The primary cultured mesencephalic astrocytes were nonpretreated or pretreated with vehicle (DMSO) or Cur $(1,3$, and 10) $(\mu \mathrm{M})$ for 30 min and then incubated with PBS, $\mathrm{MPP}^{+}(100 \mu \mathrm{M})$, or LPS $(1 \mu \mathrm{g} / \mathrm{mL})$ for $48 \mathrm{~h}$. The cell viability was determined with MTT. LDH release was measured by the LDH diagnostic kit. Nuclear condensation was assessed by staining with Hoechst33342 (magnification 200x). Data are presented as mean \pm SD of three independent experiments, ${ }^{*} P<0.05,{ }^{* *} P<0.01$, and ${ }^{* * *} P<0.001$ compared to the control group; ${ }^{\#} P<0.05$, and ${ }^{\# *} P<0.01$ compared to the $\mathrm{MPP}^{+}$or LPS treatment alone group.

the mesencephalic astrocytes were exposed to $\mathrm{MPP}^{+}$and LPS, the MDA amount in culture medium increased significantly. Being cotreated with Cur, the amount of MDA decreased markedly in the mesencephalic astrocytes (Figure 3(c)). These data suggested that Cur decreased the increased ROS and MDA amounts induced by $\mathrm{MPP}^{+}$and LPS in the primary mouse mesencephalic astrocytes. Mesencephalic Astrocytes Induced by $\mathrm{MPP}^{+}$and LPS. It was reported that curcumin generated $\mathrm{H}_{2} \mathrm{O}_{2}$ in astrocytes [32]. In order to explore the role of Cur in protecting the astrocytes, we next examined the $\mathrm{H}_{2} \mathrm{O}_{2}$ product and GSH-Px activity in the mouse mesencephalic astrocytes treated with Cur alone or combination with $\mathrm{MPP}^{+}$and LPS. As shown in Figure 4, the $\mathrm{H}_{2} \mathrm{O}_{2}$ products did not significantly change in the mouse mesencephalic astroytes after being exposed to $\mathrm{MPP}^{+}$and LPS, as well as to Cur (Figure 4(a)). The GSH-Px activity significantly decreased in the mouse mesencephalic astroytes induced by $\mathrm{MPP}^{+}$, not by LPS. Cur attenuated the 
Control

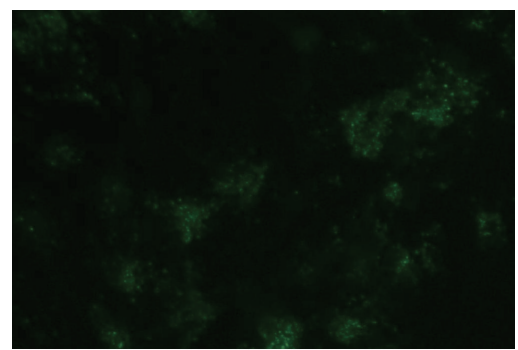

Curcumin
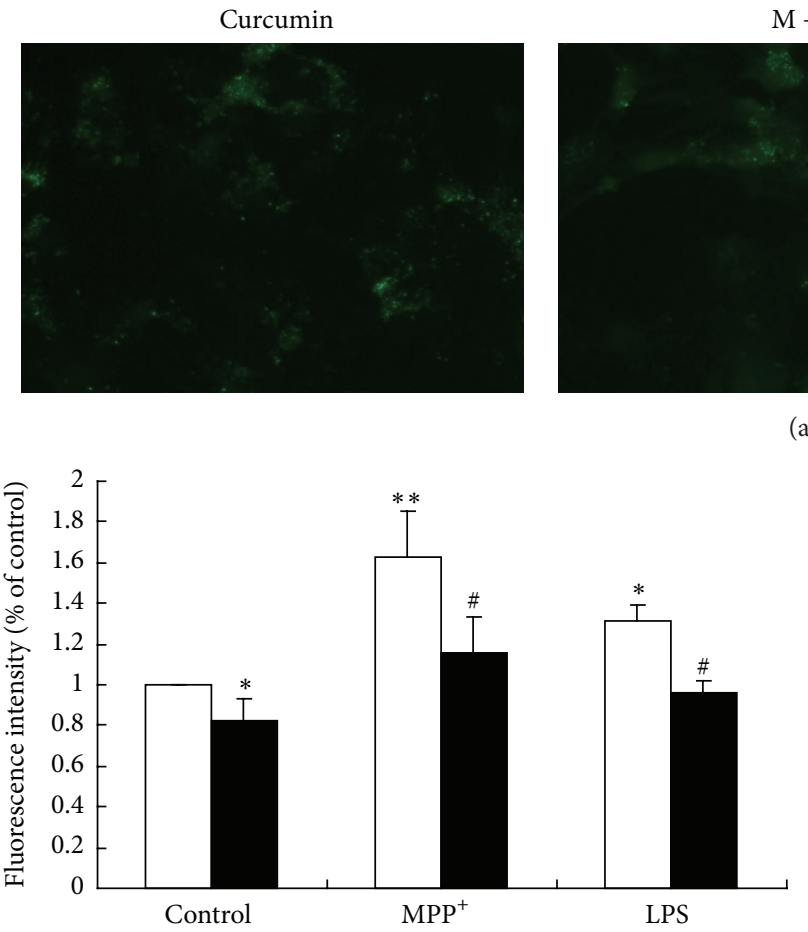

$\square$ Control

a Curcumin

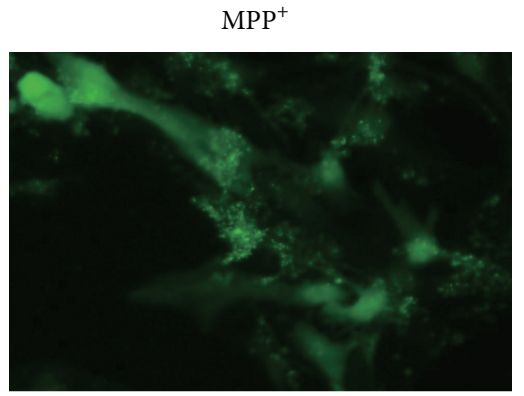

$M+C$

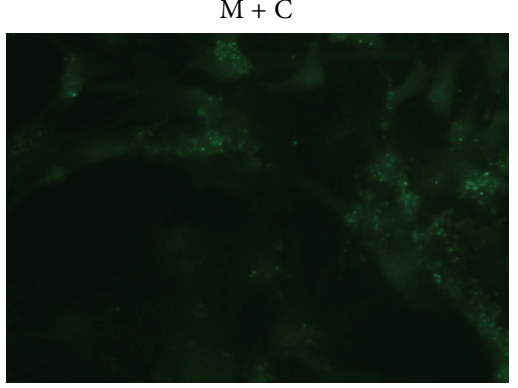

(a)
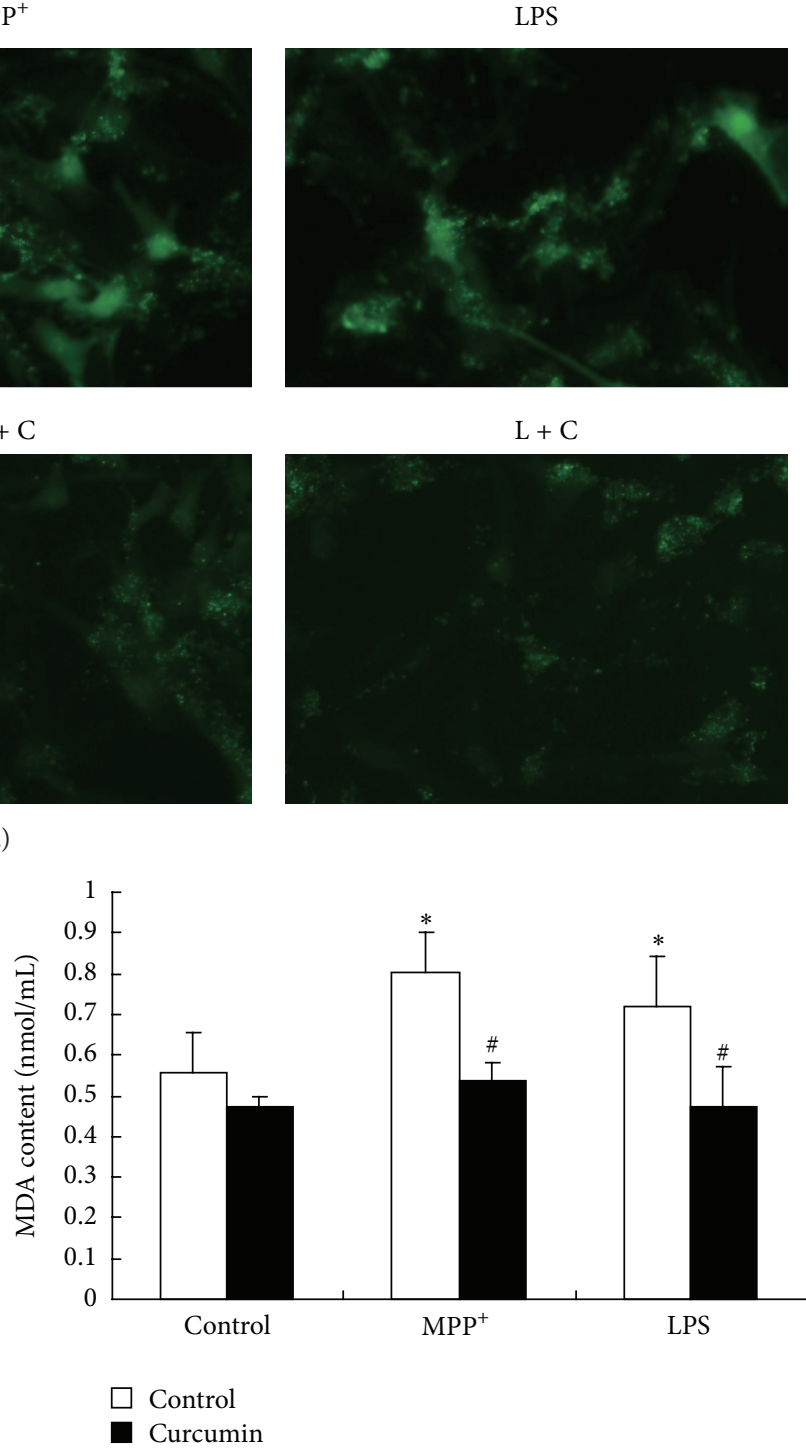

(c)

(b)

FIGURE 3: Cur decreased ROS and MDA productions in primary mesencephalic astrocytes. (a) DCFH-DA fluorescence (green) images of the primary cultured mesencephalic astrocytes. (b) Quantification of DCFH-DA fluorescence intensity. (c) MDA assay in medium of the mesencephalic astrocytes. The primary cultured mesencephalic astrocytes were nonpretreated or pretreated with vehicle (DMSO) or Cur $(3 \mu \mathrm{M})$ for $30 \mathrm{~min}$ and then incubated with PBS, MPP ${ }^{+}$, or LPS for $48 \mathrm{~h}$. The cells were loaded with DCFH-DA ( $50 \mu \mathrm{M}$ final concentration) in DMEM for $30 \mathrm{~min}$ in the dark and fixed by $4 \%$ formaldehyde. After rinsing cells with PBS three times, cells were observed using a fluorescent microscope (magnification 200x). MDA amount was measured by using the MDA diagnostic kit. Data are presented as mean \pm SD of three independent experiments, ${ }^{*} P<0.05$ and ${ }^{* *} P<0.01$ compared to the control group; ${ }^{\#} P<0.05$ compared to the MPP ${ }^{+}$or LPS treatment alone group.

decrease of GSH-Px activity in the mouse mesencephalic astroytes induced by $\mathrm{MPP}^{+}$(Figure 4(b)). Both Cur and DAS (a CYP2E1 positive inhibitor) significantly ameliorated cell viability of the mouse mesencephalic astroytes after being exposed to MPP ${ }^{+}$LPS, and EthOH (Figure 4(c)).

The data implied that the effect of Cur on the decrease of ROS and MDA in the primary mouse mesencephalic astrocytes induced by $\mathrm{MPP}^{+}$and LPS was not caused by promoting $\mathrm{H}_{2} \mathrm{O}_{2}$ production. Cur as well as DAS protected the mouse mesencephalic astroytes from $\mathrm{MPP}^{+}$- and LPSinduced cytotoxicities.

\subsubsection{Cur Inhibited Both CYP2E1 Expression and Activity} in the Mouse Mesencephalic Astrocytes Induced by MPP and LPS. Our previous work showed that CYP2E1 was an important responsibility for $\mathrm{MPP}^{+}$and LPS cytotoxicities [24]. A CYP2E1 inhibitor protected the mouse astroytes from 


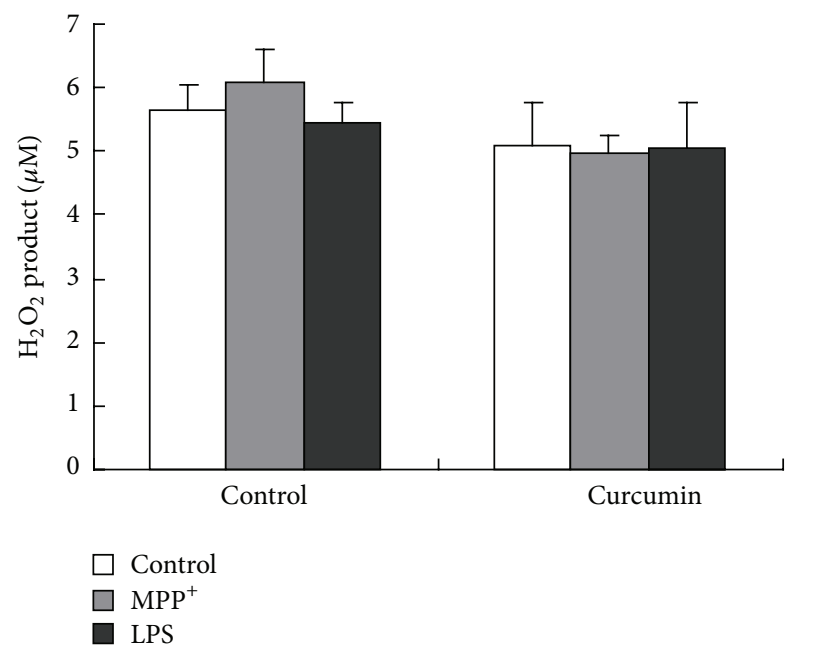

(a)

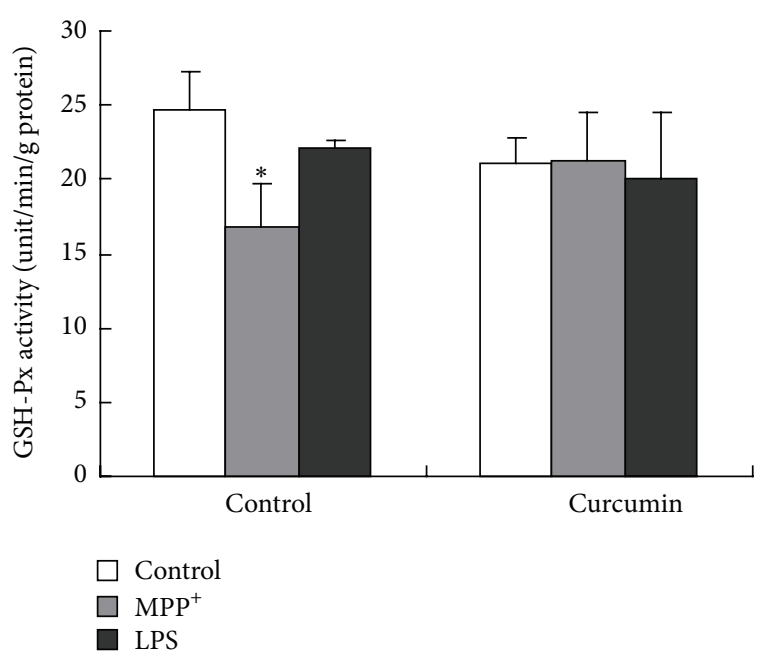

(b)

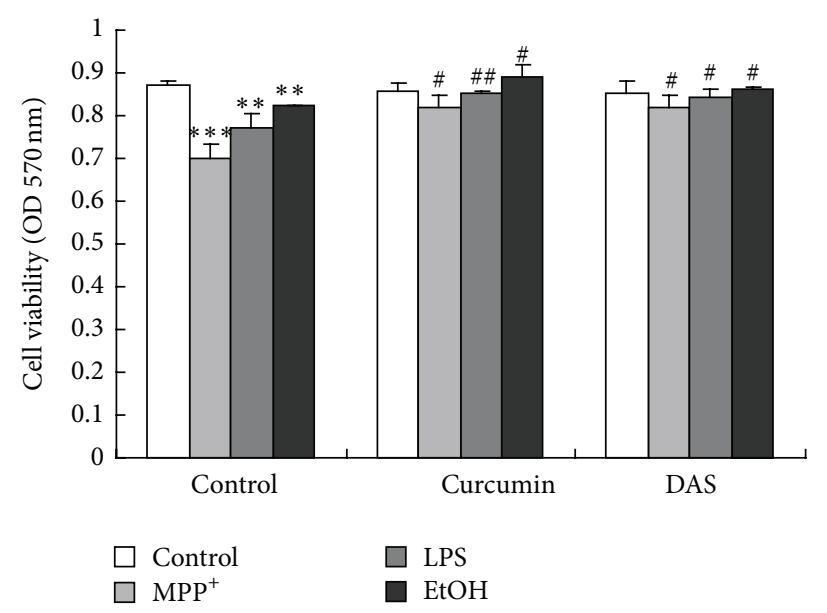

(c)

FIGURE 4: Cur as well as DAS ameliorated cell viability of the primary mesencephalic astrocytes induced by MPP ${ }^{+}$and $\mathrm{LPS}_{\text {. }}$ (a) The $\mathrm{H}_{2} \mathrm{O}_{2}$ production of the primary cultured mesencephalic astrocytes. (b) The GSH-Px activity of the primary cultured mesencephalic astrocytes. The primary cultured mesencephalic astrocytes were nonpretreated or pretreated with vehicle (DMSO) and Cur ( $3 \mu \mathrm{M})$ for 30 min and then incubated with PBS, MPP ${ }^{+}$, or LPS for $48 \mathrm{~h}$. The cultured media were measured for $\mathrm{H}_{2} \mathrm{O}_{2}$ production with $\mathrm{H}_{2} \mathrm{O}_{2}$ assay kit. And the lysates determined GSH-Px activity using GSH-Px assay kit. (c) Effect of Cur and DAS on the cell viability of the primary cultured mesencephalic astrocytes induced by $\mathrm{MPP}^{+}$and LPS. The primary cultured mesencephalic astrocytes were nonpretreated or pretreated with vehicle (DMSO), Cur $(3 \mu \mathrm{M})$, and DAS $(500 \mu \mathrm{M})$ and then incubated with PBS, MPP ${ }^{+}, \mathrm{LPS}$, or EtOH for $48 \mathrm{~h}$. EtOH was as a positive CYP2E1 inducer. Data are presented as mean $\pm \mathrm{SD}$ of three independent experiments, ${ }^{*} P<0.05,{ }^{* *} P<0.01$, and ${ }^{* * *} P<0.001$ compared to the control group; ${ }^{\#} P<0.05$ and ${ }^{\# \#} P<0.01$ compared to the $\mathrm{MPP}^{+}$or LPS treatment alone group.

$\mathrm{MPP}^{+}$- and LPS-induced cytotoxicity [24]. Presumably, the mechanism of Cur neuroprotection was probably through inhibiting CYP2E1 expression and activity in the mesencephalic astrocytes. In order to test this probability, we further investigated the effects of Cur on the CYP2E1 expression and activity in the mesencephalic astrocytes induced by $\mathrm{MPP}^{+}$, LPS and ethyl alcohol (EtOH). EtOH was a positive control of CYP2E1 inducer in this experiment. The results showed that when the mesencephalic astrocytes were exposed to $\mathrm{MPP}^{+}$, LPS, and EtOH, the CYP2E1 mRNA increased by 325\%, $222 \%$, and $292 \%$, respectively. Furthermore, Cur almost abolished the increase of CYP2E1 expression induced by $\mathrm{MPP}^{+}$,
LPS, and EtOH at mRNA level (Figure 5(a)). Similarly, the CYP2E1 immunostaining was much stronger in the mouse mesencephalic astrocytes after exposure to $\mathrm{MPP}^{+}$, LPS, and $\mathrm{EtOH}$ (Figure 5(c)). Semiquantitative analysis showed that the mean optical density of CYP2E1 increased to $187 \%, 161 \%$, and $175 \%$, respectively, and Cur almost abolished the increase of CYP2E1 expression induced by MPP ${ }^{+}$, LPS, and EtOH at protein level (Figure 5(b)). Since the expression of CYP2E1 was induced by $\mathrm{MPP}^{+}$, LPS, and EtOH in the mouse mesencephalic astrocytes, what happened to the activity of CYP2E1 in $\mathrm{MPP}^{+}$, LPS, and EtOH-exposed mesencephalic astrocytes? We measured the CYP2E1 activity by the hydroxylation of 


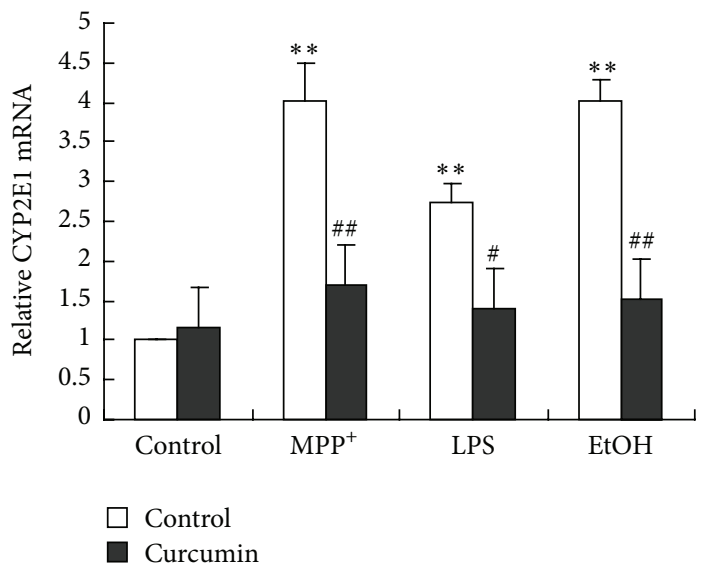

(a)

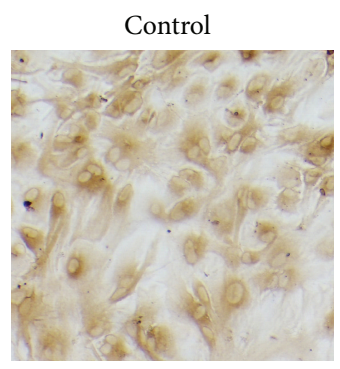

Curcumin

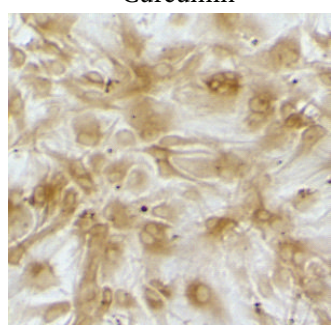

$\mathrm{MPP}^{+}$

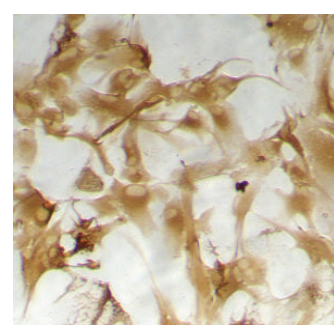

$M+C$

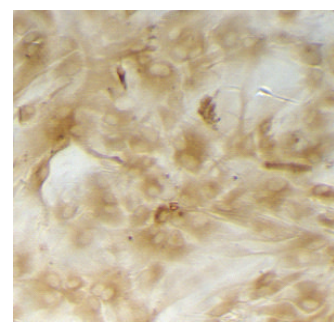

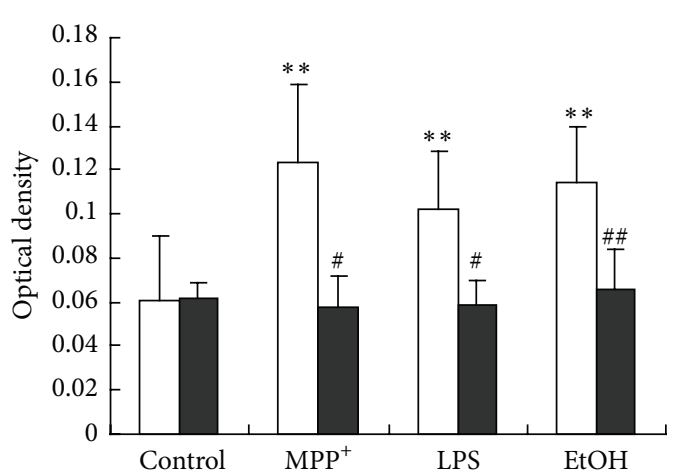

$\square$ Control

- Curcumin

(b)

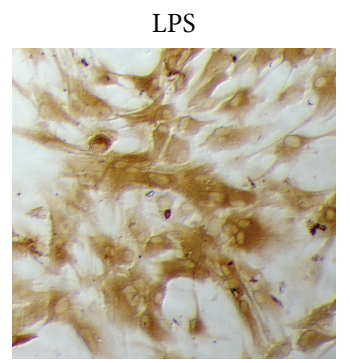

$\mathrm{L}+\mathrm{C}$

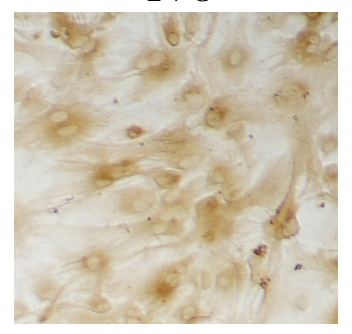

(c)

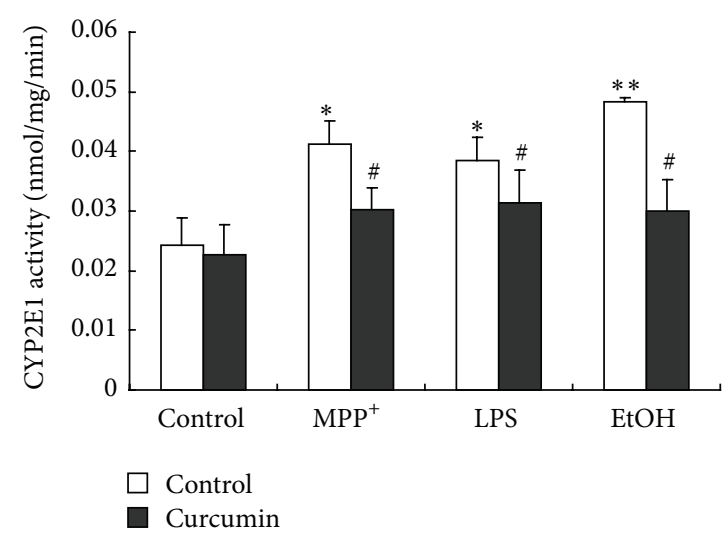

(d)

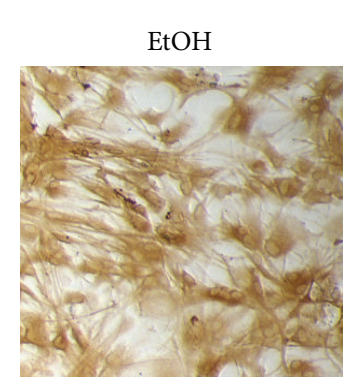

E + C

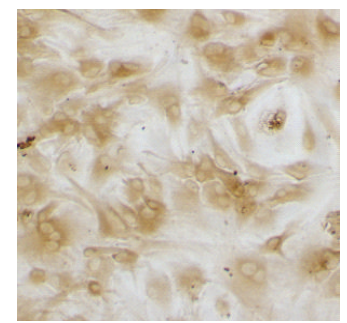

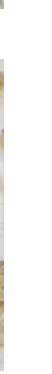


p-nitrophenol to 4-nitrocatechol. The results showed that the CYP2E1 activity of the mouse mesencephalic astrocytes increased by 1.69-fold, 1.58-fold, and 1.83-fold after exposing to $\mathrm{MPP}^{+}$, LPS, and EtOH, respectively, (Figure 5(d)). Cur substantially inhibited both the increase of CYP2E1 expression and activity in the mouse mesencephalic astrocytes induced by $\mathrm{MPP}^{+}$, LPS, and EtOH. However, Cur treatment alone seemed to have little effect on the constitutive CYP2E1 expression and activity.

The data implied that Cur, as well as DAS, inhibited both CYP2E1 expression and activity in the mouse mesencephalic astroytes induced by $\mathrm{MPP}^{+}$, LPS, and $\mathrm{EtOH}$.

3.2. Discussion. At present, if not all, most of the disabling clinical abnormalities of PD are attributed to a profound decrease in brain dopamine content in the striatum, which is induced by the remarkable loss of dopaminergic neurons in the substantia nigra pars compacta $(\mathrm{SNpc})[12]$. Therefore, the most potent treatment for PD remains the administration of levodopa (L-dopa), a precursor of dopamine, to alleviate PD symptoms. However, the chronic administration of L-dopa often produces motor and psychiatric side effects, which may limit L-dopa use [31]. So it is expected to find the natural compounds with the protective effect and no or less side effects for treatment of PD.

Recent studies have proven that Cur is a strong candidate in the prevention or treatment of major disabling age-related neurodegenerative diseases like Alzheimer's disease, $\mathrm{PD}$, and stroke $[7,8,33]$. Cur can effectively protect against ethanolinduced liver damage [34] and ethanol-induced central nervous system neurodegeneration in vivo [35]. It can directly protect the SHSY-5Y cells from $\mathrm{MPP}^{+}$toxicity [33]. Low doses of Cur can decrease the 6-hydroxydopamine- and dopamine-induced neurotoxicities in vivo $[36,37]$. Current studies show that Cur protects SH-SY5Y and PC12 cells from $\alpha$-synuclein-induced cytotoxicities through antioxidation and scavenging-free radical $[38,39]$. However, there is little information about what are the effects of Cur on the mesencephalic astrocytes which maintain homeostasis and protect against the endogenous and exogenous toxicities in the central nervous system. In the present study, we investigated the effects of Cur on the primary mouse mesencephalic astrocytes which play a crucial role in PD. We demonstrated that Cur significantly protected against $\mathrm{MPP}^{+}$- and LPSinduced mouse mesencephalic astrocytes damage at low concentration $(1 \mu \mathrm{M}-10 \mu \mathrm{M})$. In contrast, high concentrations of Cur $(30 \mu \mathrm{M}, 50 \mu \mathrm{M})$ were cytotoxicity to the mesencephalic astrocytes (Figures 1(a), 1(b), and 1(c)). Therefore, it may not be a simple stoichiometric reaction and the function of Cur was biphasic: Cur had nontoxicity and protective effect on the mesencephalic astrocytes at low concentrations (no more than $30 \mu \mathrm{M}$ ), while at high concentrations (more than $30 \mu \mathrm{M}$ ), Cur promoted the mesencephalic astrocytes damage. The reason was probably that Cur had multiple actions, such as antioxidation [4], scavenging-free radical [5], and inducing apoptosis [40].

Oxidative stress plays an important role in $\mathrm{PD}$, and dopamine-rich areas of the brain, such as mesencephalon, are particularly vulnerable to oxidative stress, because metabolism of dopamine itself leads to enhancement of ROS generation [41]. Studies showed that Cur served as a chelator and directly bound to $\mathrm{Fe}^{2+}$, which catalyzes formation of free radicals via the Fenton reactions [42]. Our results also showed that Cur attenuated the three toxins-induced increases of ROS and MDA (lipid peroxidation production). It has reported that Cur may terminate lipid peroxidation by induction of enzymatic and nonenzymatic antioxidants [43]. Accordingly, the reduction of ROS and MDA afforded by Cur in the mouse mesencephalic astrocytes induced by $\mathrm{MPP}^{+}$, LPS is likely attributable to its antioxidant effects. Recent study reported that Cur generated $\mathrm{H}_{2} \mathrm{O}_{2}$ in astrocytes [32]. However, our study showed that Cur did not significantly promote the $\mathrm{H}_{2} \mathrm{O}_{2}$ generation in the mouse mesencephalic astrocytes. The possible reason was that the concentration of Cur that we used was much lower $(3 \mu \mathrm{M})$ than that in report [32]. CYP2E1 is likely to be involved in the metabolism of the endogenous and exogenous compounds, which can cause neurodegenerative diseases such as PD [44]. In addition, CYP2E1 exhibits a high rate of oxidase activity that causes the formation of ROS during its catalytic cycle [16]. The CYP2E1 activation increases ROS production in astrocytes [24]. In this study, we found that Cur attenuated the primary cultured mouse mesencephalic astrocytes damage and apoptosis along with the decrease of ROS and MDA production induced by $\mathrm{MPP}^{+}$and LPS. Moreover, Cur as well as DAS, a CYP2E1 positive inhibitor [45], ameliorated the cell viability in the mesencephalic astrocytes induced by $\mathrm{MPP}^{+}$and LPS. These data implied that the inhibition of CYP2E1 was involved in the protection of Cur in the mesencephalic astrocytes. Therefore, in the next step, we investigate the effects of Cur on CYP2E1 expression and activity in mesencephalic astrocytes after being exposed to $\mathrm{MPP}^{+}$and LPS. Consistently, $\mathrm{MPP}^{+}$, LPS, and EtOH virtually triggered the CYP2E1 expression and enzymatic activity in mesencephalic astrocytes. Here, EtOH was a positive control of CYP2E1 inducer in this experiment. And Cur significantly lowered the increase of the CYP2E1 expression and activity in mesencephalic astrocytes induced by $\mathrm{MPP}^{+}$, LPS, and EtOH. Our previous work showed that the inhibition of CYP2E1 by DAS completely protected astrocytes from $\mathrm{MPP}^{+}$, LPS, and $\mathrm{EtOH}$-induced oxidative stress [24]. It was also found that Cur as well as DAS ameliorated the cell viability of the mesencephalic astrocytes induced by $\mathrm{MPP}^{+}$, LPS, and EtOH in this study. These data imply that Cur protected the mesencephalic astrocytes from $\mathrm{MPP}^{+}$and LPS. And the potential mechanism was that Cur inhibited CYP2E1 expression and activity and decreased the ROS generation subsequently in the mesencephalic astrocytes (Figure 6). It was reported Cur alleviated ethanol-induced hepatocytes oxidative damage involving heme oxygenase-1 (HO-1) induction [46]. Cur also potently induced HO-1 expression and activity in rat astrocytes [47]. HO-1 was the rate-limiting enzyme decomposing heme into biliverdin, free iron, and carbon monoxide (CO) by adding an oxygen molecule to the porphyrin ring of heme. $\mathrm{CO}$ inhibited ethanol-induced CYP2E1 activity and hepatotoxicity but had no influence 


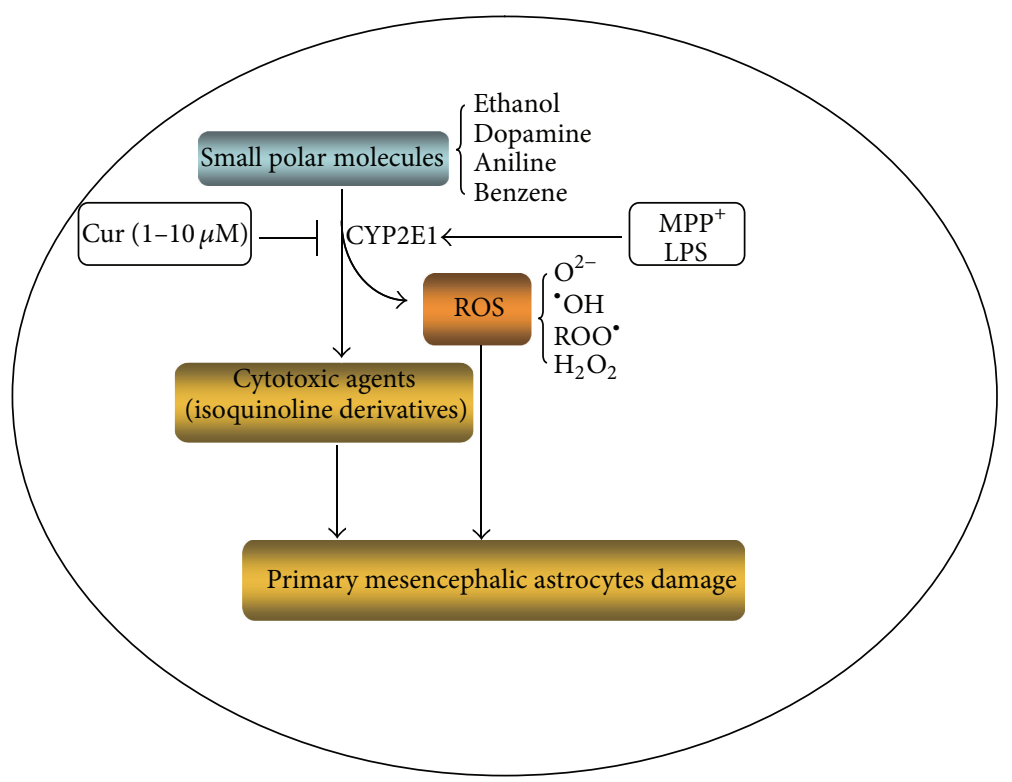

FIgURE 6: The schematic mechanism of Cur in protecting against $\mathrm{MPP}^{+}$- and LPS-induced cytotoxicities in the primary mesencephalic astrocytes. CYP2E1 is a main enzyme catalyzing the small polar molecules into oxgen ions, peroxides, and other cytotoxic agents such as isoquinoline derivatives. $\mathrm{MPP}^{+}$and LPS activated the CYP2E1 and induced mesencephalic astrocyte damage. Cur inhibited the CYP2E1 expression and activity, reduced the ROS production, and protected against $\mathrm{MPP}^{+}$- and LPS-induced cytotoxicities in the mesencephalic astrocytes.

on CYP2E1 protein expression [48]. Together, Cur might protect against $\mathrm{MPP}^{+}$- and LPS-induced toxicities in the mesencephalic astrocytes not only by increasing the HO-1 activity but also by inhibiting CYP2E1 expression and activity.

\section{Conclusion}

Our work points to several important conclusions. First, we report for the first time that Cur can protect against $\mathrm{MPP}^{+}$- and LPS-induced cytotoxicities in the primary mouse mesencephalic astrocytes. And inhibition of both CYP2E1 expression and activity is suggested as the mechanism of protective effects of Cur against $\mathrm{MPP}^{+}$- and LPS-induced injuries in the primary mouse mesencephalic astrocytes. Second, Cur decreases the CYP2E1 expression and activity in the primary mouse mesencephalic astrocytes, indicating that Cur affects metabolism of the endogenous and exogenous compounds in the central nervous system. Taken together, this study provides evidence to explore the possible use of Cur, a very low toxic natural compound as a therapeutic approach in PD at low concentration, and provides new insight into understanding the role of Cur in the drug metabolism enzymes in the central nervous system.

\section{Abbreviations}

Cur: Curcumin

ROS: Reactive oxygen species

PD: Parkinson's disease

CYPs: Cytochrome P450 enzymes

CYP2E1: Cytochrome P450 2E1

$\mathrm{MPP}^{+}: \quad$ 1-Methyl-4-phenylpyridinium ion

$\begin{array}{ll}\text { LPS: } & \text { Lipopolysaccharide } \\ \text { MDA: } & \text { Maleic dialdehyde } \\ \mathrm{H}_{2} \mathrm{O}_{2}: & \text { Hydrogen peroxide } \\ \text { GSH-Px: } & \text { Glutathione peroxidase } \\ \text { DMEM: } & \text { Dulbecco's modified Eagle's medium } \\ \text { MTT: } & \text { 3-(4,5-Dimethylthiazol-2-yl) } \\ & \text { 2,5-Diphenyltetrazolium bromide } \\ \text { LDH: } & \text { Lactate dehydrogenase } \\ \text { DAB: } & \text { Diaminobenzidine } \\ \text { DAS: } & \text { Diallylsulphide } \\ \text { EtOH: } & \text { Ethyl alcohol } \\ \text { DCFH-DA: } 2^{\prime}, 7^{\prime} \text {-Dichlorofluorescein diacetate } \\ \text { FBS: } & \text { Fetal bovine serum } \\ \text { DMSO: } & \text { Dimethyl sulfoxide } \\ \text { L-dopa: } & \text { Levodopa. }\end{array}$

\section{Conflict of Interests}

The authors declare that there is no conflict of interests.

\section{Authors' Contribution}

H.-Y. Gui and R.-N. Chen contributed equally to this work.

\section{Acknowledgments}

This work is supported by the Natural Science Foundation of China (nos. 30772616, 81173128), the National Key Basic Research Program of China (no. 2009CB521906), the 
project funded by the Priority Academic Program Development of Jiangsu Higher Education Institutions, Ministry of Education, Science, and Technology Development Center (2012323411000), Ministry and Education of PRC (20123234110005), and the National Institutes of Health of USA (USA, F05AT003019).

\section{References}

[1] T. Santel, G. Pflug, N. Y. A. Hemdan et al., "Curcumin inhibits glyoxalase 1-a possible link to its anti-inflammatory and antitumor activity," PLoS ONE, vol. 3, no. 10, Article ID e3508, 2008.

[2] D. Lu, T. Lin, X. Wo, P. Wang, Y. Zhou, and Z. Yang, "Proteomic research on anti-atherosclerosis mechanism of curcumin in RAW264.7," Zhongguo Zhongyao Zazhi, vol. 36, no. 9, pp. 12071211, 2011.

[3] B. B. Aggarwal, A. Kumar, and A. C. Bharti, "Anticancer potential of curcumin: preclinical and clinical studies," Anticancer Research, vol. 23, no. 1 A, pp. 363-398, 2003.

[4] S. Toda, T. Miyase, and H. Arichi, "Natural antioxidants. III. Antioxidative components isolated from rhizome of Curcuma longa L," Chemical and Pharmaceutical Bulletin, vol. 33, no. 4, pp. 1725-1728, 1985.

[5] A. Barzegar and A. A. Moosavi-Movahedi, "Intracellular ROS protection efficiency and free radical-scavenging activity of curcumin," PLoS ONE, vol. 6, no. 10, Article ID e26012, 2011.

[6] R. K. Maheshwari, A. K. Singh, J. Gaddipati, and R. C. Srimal, "Multiple biological activities of curcumin: a short review," Life Sciences, vol. 78, no. 18, pp. 2081-2087, 2006.

[7] G. M. Cole, B. Teter, and S. A. Frautschy, "Neuroprotective effects of curcumin," Advances in Experimental Medicine and Biology, vol. 595, pp. 197-212, 2007.

[8] R. B. Mythri and M. M. Srinivas Bharath, "Curcumin: a potential neuroprotective agent in Parkinson's disease," Current Pharmaceutical Design, vol. 18, no. 1, pp. 91-99, 2012.

[9] S. S. Agrawal, S. Gullaiya, V. Dubey et al., "Neurodegenerative shielding by curcumin and its derivatives on brain lesions induced by 6-OHDA model of Parkinson's disease in albino wistar rats," Cardiovascular Psychiatry and Neurology, vol. 2012, Article ID 942981, 8 pages, 2012.

[10] W. Shao, S. Z. Zhang, M. Tang et al., "Suppression of neuroinflammation by astrocytic dopamine D2 receptors via $\alpha \mathrm{B}$ crystallin,” Nature, vol. 494, no. 7435, pp. 90-94, 2013.

[11] A. E. Lang and A. M. Lozano, "Parkinson's disease. First of two parts," The New England Journal of Medicine, vol. 339, pp. 10441053, 1998.

[12] A. Siderowf and M. Stern, "Update on Parkinson disease," Annals of Internal Medicine, vol. 138, no. 8, pp. 651-658, 2003.

[13] A. H. V. Schapira, "Etiology of Parkinson's disease," Neurology, vol. 66, no. 10, supplement 4, pp. S10-S23, 2006.

[14] C. Zhou, Y. Huang, and S. Przedborski, "Oxidative stress in Parkinson's disease: a mechanism of pathogenic and therapeutic significance," Annals of the New York Academy of Sciences, vol. 1147, pp. 93-104, 2008.

[15] A. A. Caro and A. I. Cederbaum, "Oxidative stress, toxicology, and pharmacology of CYP2E1," Annual Review of Pharmacology and Toxicology, vol. 44, pp. 27-42, 2004.
[16] G. Ekstrom and M. Ingelman-Sundberg, "Rat liver microsomal NADPH-supported oxidase activity and lipid peroxidation dependent on ethanol-inducible cytochrome P-450 (P450IIE1)," Biochemical Pharmacology, vol. 38, no. 8, pp. 13131319, 1989.

[17] T. Hansson, N. Tindberg, M. Ingelman-Sundberg, and C. Kohler, "Regional distribution of ethanol-inducible cytochrome P450 IIE1 in the rat central nervous system," Neuroscience, vol. 34, no. 2, pp. 451-463, 1990.

[18] C. Montoliu, M. Sancho-Tello, I. Azorin et al., "Ethanol increases cytochrome P4502E1 and induces oxidative stress in astrocytes," Journal of Neurochemistry, vol. 65, no. 6, pp. 25612570, 1995.

[19] N. Tindberg, H. A. Baldwin, A. J. Cross, and M. IngelmanSundberg, "Induction of cytochrome P450 2E1 expression in rat and gerbil astrocytes by inflammatory factors and ischemic injury," Molecular Pharmacology, vol. 50, no. 5, pp. 1065-1072, 1996.

[20] M. Warner and J. Å. Gustafsson, "Effect of ethanol on cytochrome P450 in the rat brain," Proceedings of the National Academy of Sciences of the United States of America, vol. 91, no. 3, pp. 1019-1023, 1994.

[21] C. Pardini, F. Vaglini, C. Viaggi, A. Caramelli, and G. U. Corsini, "Role of CYP2E1 in the mouse model of MPTP toxicity," Parkinsonism and Related Disorders, vol. 14, no. 2, pp. S119-S123, 2008.

[22] F. Vaglini, C. Pardini, C. Viaggi, C. Bartoli, D. Dinucci, and G. U. Corsini, "Involvement of cytochrome P450 2E1 in the 1-methyl4-phenyl-1,2,3,6-tetrahydropyridine-induced mouse model of Parkinson's disease," Journal of Neurochemistry, vol. 91, no. 2, pp. 285-298, 2004.

[23] T. Ivanova and C. Beyer, "Estrogen regulates tyrosine hydroxylase expression in the neonate mouse midbrain," Journal of Neurobiology, vol. 54, no. 4, pp. 638-647, 2003.

[24] C. Hao, W. Liu, X. Luan et al., "Aquaporin-4 knockout enhances astrocyte toxicity induced by 1-methyl-4-phenylpyridinium ion and lipopolysaccharide via increasing the expression of cytochrome P4502E1," Toxicology Letters, vol. 198, no. 2, pp. 225-231, 2010.

[25] K. J. Sipe, R. Dantzer, K. W. Kelley, and J. A. Weyhenmeyer, "Expression of the $75 \mathrm{kDA}$ TNF receptor and its role in contactmediated neuronal cell death," Molecular Brain Research, vol. 62, no. 2, pp. 111-121, 1998.

[26] Y. Peng, W. Liu, J. Xiong et al., "Down regulation of differentiated embryonic chondrocytes 1 (DEC1) is involved in 8methoxypsoralen-induced apoptosis in HepG2 cells," Toxicology, vol. 301, no. 1-3, pp. 58-65, 2012.

[27] Y. Yuan, X. Xue, R. B. Guo, X. L. Sun, and G. Hu, "Resveratrol enhances the antitumor effects of temozolomide in glioblastoma via ROS-dependent AMPK-TSC-mTOR signaling pathway," CNS Neuroscience and Therapeutics, vol. 18, no. 7, pp. 536546, 2012.

[28] H. H. Draper and M. Hadley, "Malondialdehyde determination as index of lipid peroxidation," Methods in Enzymology, vol. 186, pp. 421-431, 1990.

[29] Y. Wang and L. Fu, "Forms of selenium affect its transport, uptake and glutathione peroxidase activity in the Caco-2 cell model," Biological Trace Element Research, vol.149, no. 1, pp. 110116, 2012.

[30] L. A. Reinke and M. J. Moyer, "A microsomal oxidation which is highly inducible by ethanol," Drug Metabolism and Disposition, vol. 13, no. 5, pp. 548-552, 1985. 
[31] D. R. Koop, "Hydroxylation of p-nitrophenol by rabbit ethanolinducible cytochrome P-450 isozyme 3a," Molecular Pharmacology, vol. 29, no. 4, pp. 399-404, 1986.

[32] H. Erlank, A. Elmann, R. Kohen, and J. Kanner, "Polyphenols activate $\mathrm{Nrf} 2$ in astrocytes via $\mathrm{H} 2 \mathrm{O} 2$, semiquinones, and quinones," Free Radical Biology and Medicine, vol. 51, no. 12, pp. 2319-2327, 2011.

[33] S. Yu, W. Zheng, N. Xin et al., "Curcumin prevents dopaminergic neuronal death through inhibition of the c-Jun N-terminal kinase pathway," Rejuvenation Research, vol. 13, no. 1, pp. 55-64, 2010.

[34] A. A. Nanji, K. Jokelainen, G. L. Tipoe, A. Rahemtulla, P. Thomas, and A. J. Dannenberg, "Curcumin prevents alcoholinduced liver disease in rats by inhibiting the expression of NF$\kappa \mathrm{B}$-dependent genes," American Journal of Physiology, vol. 284, no. 2, pp. G321-G327, 2003.

[35] V. Rajakrishnan, P. Viswanathan, K. N. Rajasekharan, and V. P. Menon, "Neuroprotective role of curcumin from curcuma longa on ethanol-induced brain damage," Phytotherapy Research, vol. 13, pp. 571-574, 1999.

[36] X. X. Du, H. M. Xu, H. Jiang, N. Song, J. Wang, and J. X. Xie, "Curcumin protects nigral dopaminergic neurons by ironchelation in the 6-hydroxydopamine rat model of Parkinson's disease," Neuroscience Bulletin, vol. 28, pp. 253-258, 2012.

[37] Y. Luo, A. Hattori, J. Munoz, Z. H. Qin, and G. S. Roth, "Intrastriatal dopamine injection induces apoptosis through oxidation-involved activation of transcription factors AP-1 and NF- $\kappa$ B in rats," Molecular Pharmacology, vol. 56, no. 2, pp. 254$264,1999$.

[38] M. S. Wang, S. Boddapati, S. Emadi, and M. R. Sierks, "Curcumin reduces $\alpha$-synuclein induced cytotoxicity in Parkinson's disease cell model," BMC Neuroscience, vol. 11, article 57, 2010.

[39] Z. Liu, Y. Yu, X. Li, C. A. Ross, and W. W. Smith, "Curcumin protects against A53T alpha-synuclein-induced toxicity in a PC12 inducible cell model for Parkinsonism," Pharmacological Research, vol. 63, no. 5, pp. 439-444, 2011.

[40] H. P. Lee, T. M. Li, J. Y. Tsao, Y. C. Fong, and C. H. Tang, "Curcumin induces cell apoptosis in human chondrosarcoma through extrinsic death receptor pathway," International Immunopharmacology, vol. 13, no. 2, pp. 163-169, 2012.

[41] J. Lotharius and P. Brundin, "Pathogenesis of Parkinson's disease: dopamine, vesicles and alpha-synuclein," Nature Reviews Neuroscience, vol. 3, no. 12, pp. 932-942, 2002.

[42] Y. Jiao, J. Wilkinson IV, X. Di et al., "Curcumin, a cancer chemopreventive and chemotherapeutic agent, is a biologically active iron chelator," Blood, vol. 113, no. 2, pp. 462-469, 2009.

[43] J. Miquel, A. Bernd, J. M. Sempere, J. Díaz-Alperi, and A. Ramírez, "The curcuma antioxidants: pharmacological effects and prospects for future clinical use. A review," Archives of Gerontology and Geriatrics, vol. 34, no. 1, pp. 37-46, 2002.

[44] N. P. Kennedy and K. F. Tipton, "Ethanol metabolism and alcoholic liver disease," Essays in Biochemistry, vol. 25, pp. 137195, 1990.

[45] C. S. Lieber, "Cytochrome P-4502E1: its physiological and pathological role," Physiological Reviews, vol. 77, no. 2, pp. 517544, 1997.

[46] W. Bao, K. Li, S. Rong et al., "Curcumin alleviates ethanolinduced hepatocytes oxidative damage involving heme oxygenase-1 induction," Journal of Ethnopharmacology, vol. 128, no. 2, pp. 549-553, 2010.
[47] G. Scapagnini, C. Colombrita, M. Amadio et al., "Curcumin activates defensive genes and protects neurons against oxidative stress," Antioxidants and Redox Signaling, vol. 8, no. 3-4, pp. 395-403, 2006.

[48] P. Yao, L. Hao, N. Nussler et al., "The protective role of $\mathrm{HO}-1$ and its generated products ( $\mathrm{CO}$, bilirubin, and $\mathrm{Fe}$ ) in ethanol-induced human hepatocyte damage," American Journal of Physiology, vol. 296, no. 6, pp. G1318-G1323, 2009. 


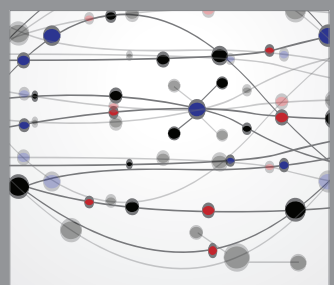

The Scientific World Journal
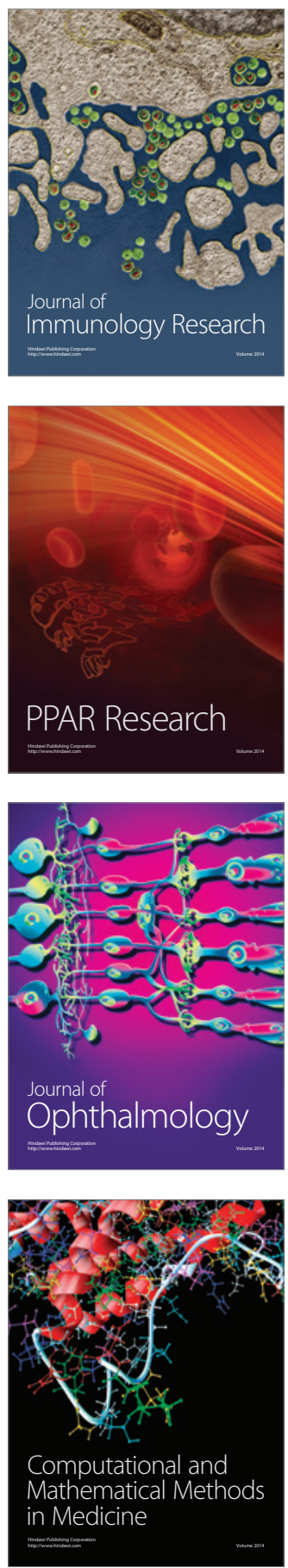

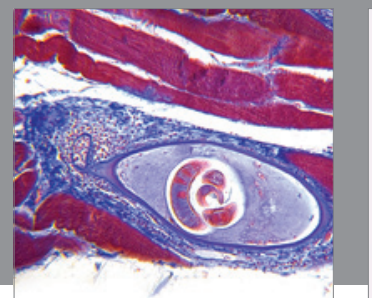

Gastroenterology

Research and Practice
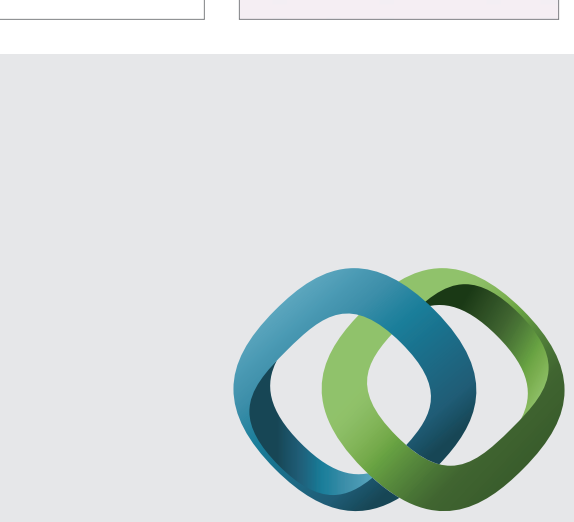

\section{Hindawi}

Submit your manuscripts at

http://www.hindawi.com
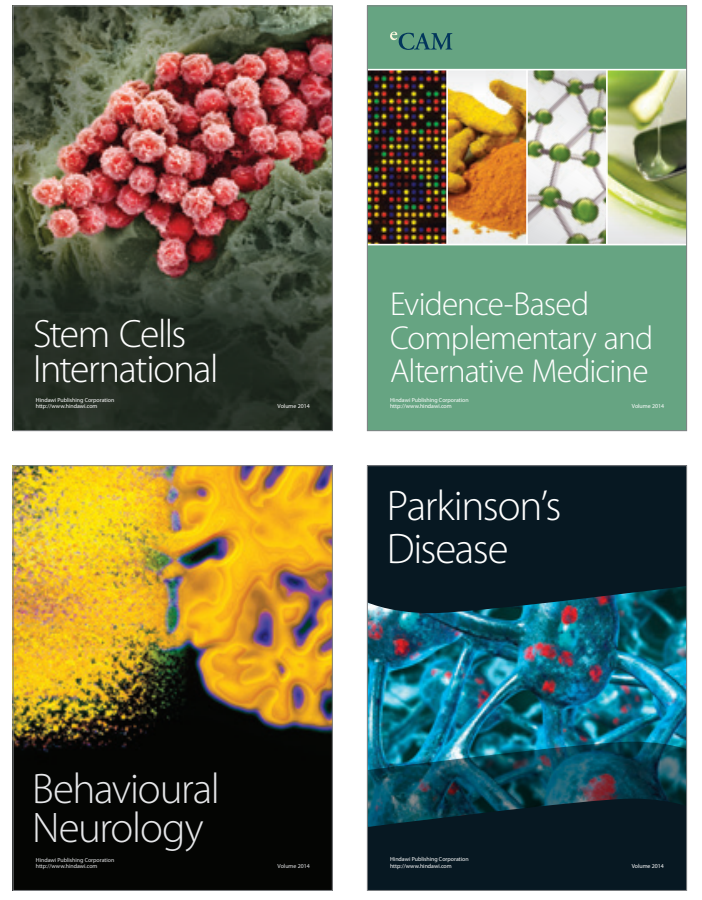
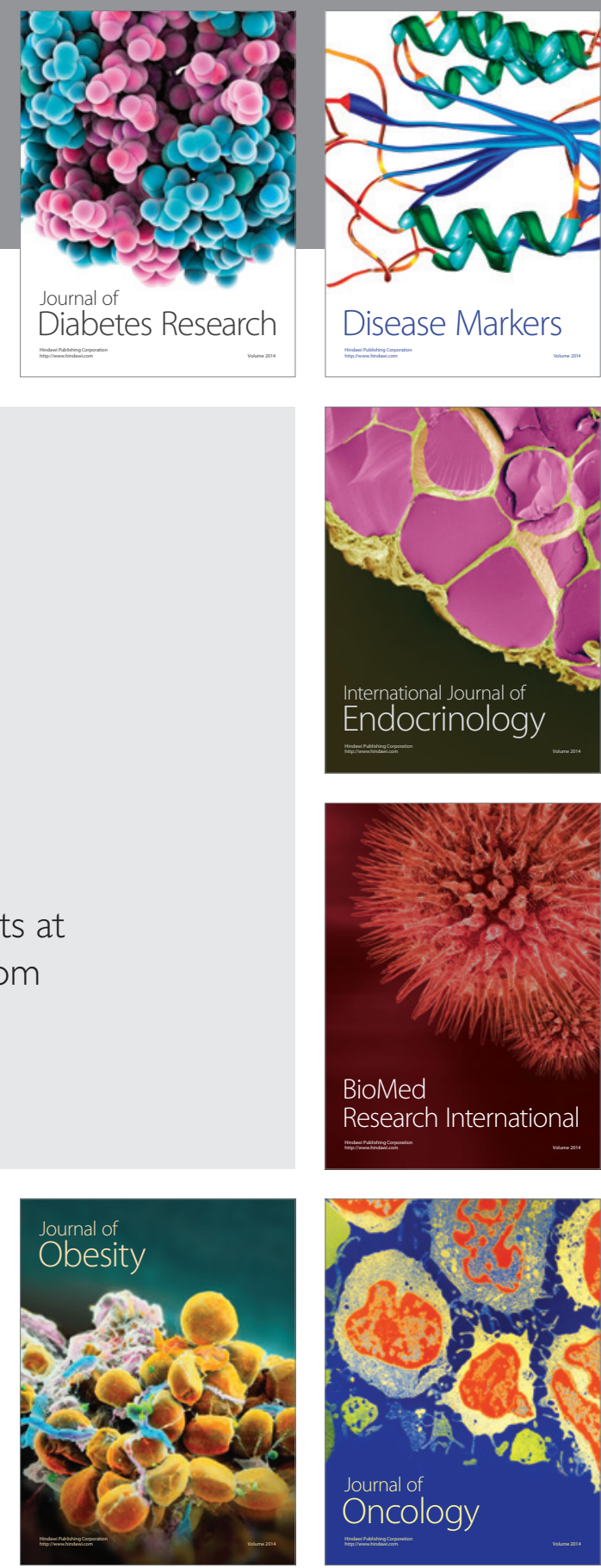

Disease Markers
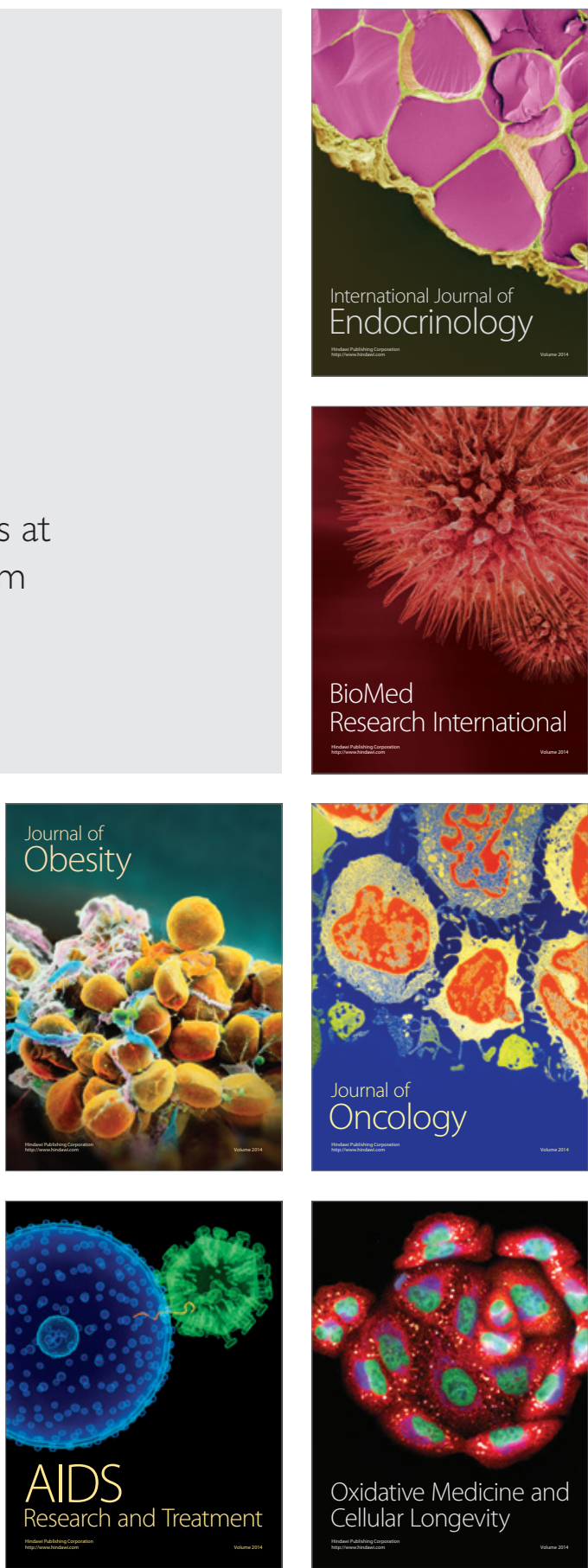